ANL-94/38

Chemical Technology Division

Chemical Technology Division

Chemical Technology Division

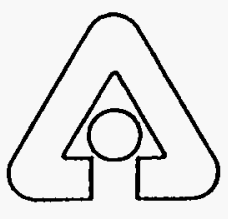

Analytical Electron Microscopy Characterization of Uranium-Contaminated Soils from the Fernald Site

FY 1993 Report

by E. C. Buck, J. C. Cunnane, N. R. Brown, and N. L. Dietz 
Argonne National Laboratory, with facilities in the states of Illinois and Idaho, is owned by the United States government, and operated by The University of Chicago under the provisions of a contract with the Department of Energy.

\section{DISCLAIMER}

This report was prepared as an account of work sponsored by an agency of the United States Government. Neither the United States Government nor any agency thereof, nor any of their employees, makes any warranty, express or implied, or assumes any legal liability or responsibility for the accuracy, completeness, or usefulness of any information, apparatus, product, or process disclosed, or represents that its use would not infringe privately owned rights. Reference herein to any specific commercial product, process, or service by trade name, trademark, manufacturer, or otherwise, does not necessarily constitute or imply its endorsement, recommendation, or favoring by the United States Government or any agency thereof. The views and opinions of authors expressed herein do not necessarily state or reflect those of the United States Government or any agency thereof.

Reproduced from the best available copy.

Available to DOE and DOE contractors from the Office of Scientific and Technical Information

P.O. Box 62

Oak Ridge, TN 37831

Prices available from (615) 576-8401

Available to the public from the

National Technical Information Service

U.S. Department of Commerce

5285 Port Royal Road

Springfield, VA 22161 


\section{DISCLAIMER}

Portions of this document may be illegible in electronic image products. Images are produced from the best available original document. 
Distribution Category:

Contaminant Plume Containment and Remediation (UC-2010)

ANL-94/38

\section{ARGONNE NATIONAL LABORATORY \\ 9700 South Cass Avenue \\ Argonne, IL 60439}

\section{ANALYTICAL ELECTRON MICROSCOPY CHARACTERIZATION OF URANIUM-CONTAMINATED SOILS FROM THE FERNALD SITE \\ FY 1993 REPORT}

by

E. C. Buck, J. C. Cunnane, N. R. Brown, and N. L. Dietz

Chemical Technology Division

October 1994

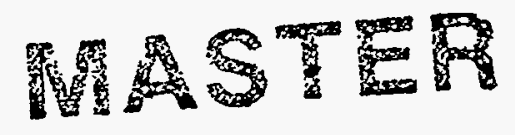

DIETRIBUTION OF THIS DOCUMENT IS UNLIMITED 


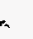


ABSTRACT $\ldots \ldots \ldots \ldots \ldots \ldots \ldots \ldots \ldots \ldots \ldots \ldots \ldots \ldots \ldots \ldots \ldots \ldots \ldots$

SUMMARY $\ldots \ldots \ldots \ldots \ldots \ldots \ldots \ldots \ldots \ldots \ldots \ldots \ldots \ldots \ldots \ldots \ldots \ldots$

I. INTRODUCTION $\ldots \ldots \ldots \ldots \ldots \ldots \ldots \ldots \ldots \ldots \ldots \ldots \ldots \ldots \ldots \ldots$

A. Analytical Electron Microscopy $\ldots \ldots \ldots \ldots \ldots \ldots \ldots \ldots \ldots \ldots$

B. Characterization Studies at Fernald Environmental Management Project ..................... 4

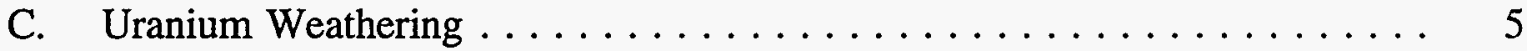

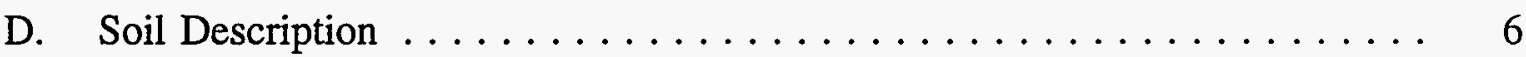

1. Source of Uranium Contamination in Fernald Soils . . . . . . . . . 6

2. Soil Components $\ldots \ldots \ldots \ldots \ldots \ldots \ldots \ldots \ldots \ldots \ldots \ldots \ldots \ldots \ldots \ldots$

II. EXPERIMENTAL METHODS AND DEVELOPMENT $\ldots \ldots \ldots \ldots \ldots$

A. Instrumental Methods $\ldots \ldots \ldots \ldots \ldots \ldots \ldots \ldots \ldots \ldots \ldots$

B. Ultramicrotomy $\ldots \ldots \ldots \ldots \ldots \ldots \ldots \ldots \ldots \ldots \ldots \ldots \ldots \ldots \ldots$

III. $\quad$ RESULTS AND DISCUSSION $\ldots \ldots \ldots \ldots \ldots \ldots \ldots \ldots \ldots \ldots \ldots$

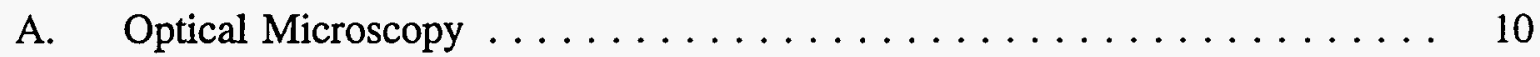

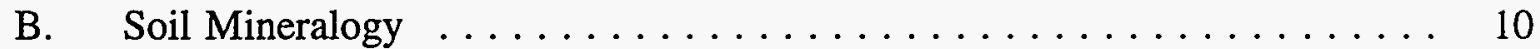

C. Identification of Uranium-Bearing Phases $\ldots \ldots \ldots \ldots \ldots \ldots \ldots$

1. Uranium in Iron Oxides . . . . . . . . . . . . . . . 13

2. Uranium Oxide Phases . . . . . . . . . . . . . . . . 17

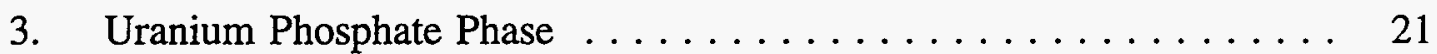

4. Calcium Uranium Oxide Phase $\ldots \ldots \ldots \ldots \ldots \ldots \ldots \ldots \ldots . \ldots \ldots$

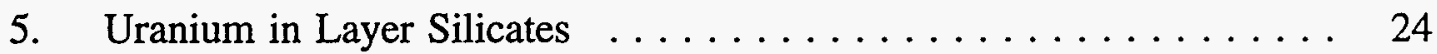

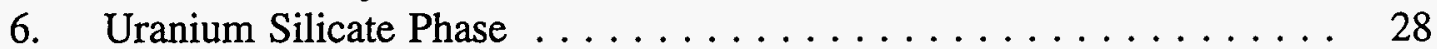

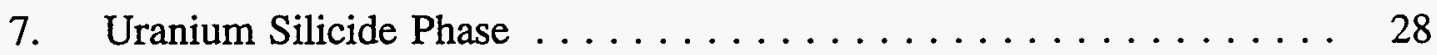

8. Uranium Phosphite Phase $\ldots \ldots \ldots \ldots \ldots \ldots \ldots \ldots \ldots \ldots$

D. Oxidation State Determination by Electron Energy Loss Spectroscopy ...................... 33

E. Estimation of Uranium Distribution and Concentration $\ldots \ldots \ldots \ldots 34$

F. Soil Remediation Support $\ldots \ldots \ldots \ldots \ldots \ldots \ldots \ldots \ldots \ldots \ldots \ldots$ 
TABLE OF CONTENTS (contd)

Page

1. Density Separation of A14 Soil . ............... 35

2. Citrate/Carbonate Extraction of Sample A14 Soil . . . . . . . . . 36

3. Dithionite/Tiron Extraction of Sample A14 Soil . . . . . . . . 38

G. Redistribution of Uranium in Fernald Soils $\ldots \ldots \ldots \ldots \ldots \ldots \ldots .40$

IV. CONCLUSIONS AND RECOMMENDATIONS $\ldots \ldots \ldots \ldots \ldots \ldots \ldots$

A. Implications for Remediation Technologies $\ldots \ldots \ldots \ldots \ldots \ldots \ldots . \ldots 42$

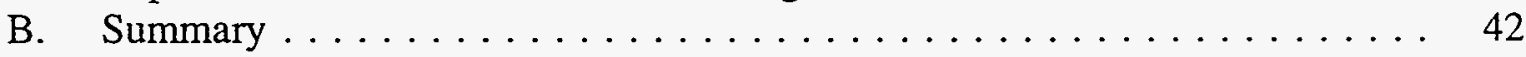

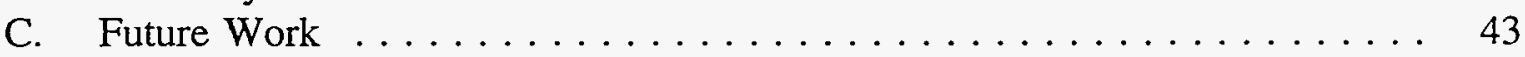

ACKNOWLEDGMENTS $\ldots \ldots \ldots \ldots \ldots \ldots \ldots \ldots \ldots \ldots \ldots \ldots \ldots \ldots \ldots \ldots \ldots$

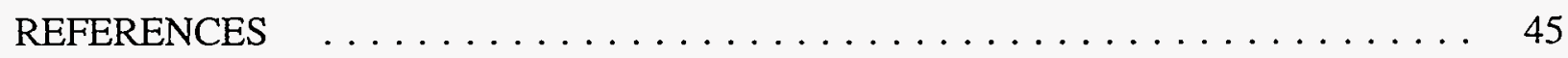

APPENDIX I. TERMINOLOGY $\ldots \ldots \ldots \ldots \ldots \ldots \ldots \ldots \ldots \ldots \ldots \ldots \ldots \ldots \ldots$ 


\section{LIST OF FIGURES}

No.

1. Low Magnification Micrographs of a Uranium Phosphate Phase ........ 9

2. Lattice Image of Chlorite (Vermiculite) with $\mathbf{c}$-axis Spacings of $\sim 15 \AA \ldots \ldots 11$

3. TEM Image of Potassium Aluminosilicate Phase, along with a Number of Zone Axis Patterns and EDS Analysis . . . . . . . . . 15

4. TEM Image of Calcium Phosphate (Apatite) Phase Identified by Electron Diffraction and EDS Analysis $\ldots \ldots \ldots \ldots \ldots \ldots \ldots \ldots$

5. Electron Diffraction Patterns of the Rhombohedral Calcium Magnesium

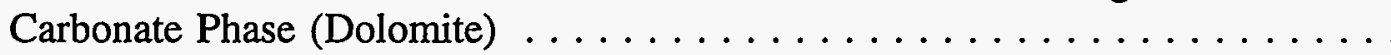

6. Uranium-Bearing Amorphous Iron Oxide Phase Found in SP4 and SP2-3 Soil . . . . . . . . . . . . . . . . . . . . . . . . . . .

7. Variation in Unit Cell Parameter with O:U Ratio in Uranium Oxide $\ldots \ldots 20$

8. Displacement of Oxygen Atoms in the $\mathrm{UO}_{2}$ Lattice Following the Incorporation of Additional Oxygen Atoms $\ldots \ldots \ldots \ldots \ldots \ldots$

9. SAED Pattern of a Uranium Oxide Taken along the [100] Zone Axis

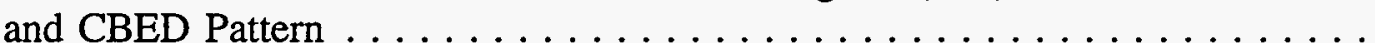

10. Uranium Phosphate Phases Dispersed among Chlorite and Other Minerals That Do Not Appear to Contain Uranium . . . . . . . . . . . . . . .

11. BSE Image of Uranium Phosphate Phase, along with TEM Image, Electron Diffraction Pattern Showing a Partially Amorphous Phase, and EDS Analysis . . . . . . . . . . . . . . . . . . . . .

12. Uranium Phosphate Phase Found in SP2-3 .............. 26

13. TEM Image of a Calcium Uranium Oxide Phase Found in SP2-3, with SAED Pattern and EDS Analysis . . . . . . . . . . . . . .

14. Micrograph of Uranium-Rich Silicate Phase Found in Clay and Identified as the Uranyl Silicate Soddyite $\left[\left(\mathrm{UO}_{2}\right)_{2} \mathrm{SiO}_{2} \cdot 2 \mathrm{H}_{2} \mathrm{O}\right]$ by Electron Diffraction and EDS Compositional Analysis 


\section{LIST OF FIGURES (contd)}

$\underline{\text { No. }}$

Title

$\underline{\text { Page }}$

15. BSE Image of $>100-\mu \mathrm{m}$ Particle Containing Uranium and Silicon,

Which Was Identified as a Uranium Silicide by EDS, TEM Image, and a Series of Electron Diffraction Patterns . . . . . . . . . . . 30

16. TEM Image of the Density-Separated A14 Soil Sample Showing

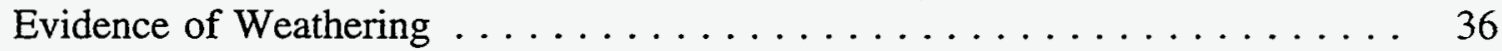

17. Example of the Ceramic-Like Uranium Phosphite Phase in

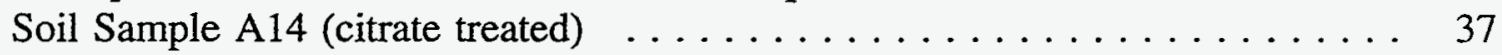

18. BSE Image Showing Uranium Oxide Surrounded by

Calcium Phosphate Phase in Sample A14 . . . . . . . . . . . . . . 39 


\section{LIST OF TABLES}

No.

Title

Page

1. Electron Diffraction Data from Layer Silicate Minerals in SP4

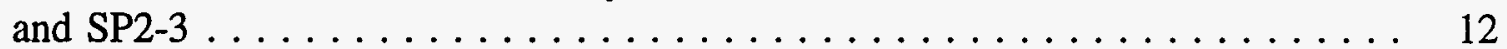

2. Electron Diffraction Data from Feldspar Phase in Sample SP4 . . . . . . 14

3. Electron Diffraction Data from Calcium Phosphate Phase ........... 14

4. Electron Diffraction Data from Dolomite $\ldots \ldots \ldots \ldots \ldots \ldots \ldots \ldots$

5. Results of EDS Analysis of Seven Iron Uranium Oxide Particles $\ldots \ldots \ldots 17$

6. Electron Diffraction Data from Uranium Oxide Phase $\ldots \ldots \ldots \ldots \ldots 21$

7. Electron Diffraction Data from Uranium Phosphate $\ldots \ldots \ldots \ldots . \ldots 22$

8. Electron Diffraction Data from a Calcium Uranium Phosphate $\ldots \ldots \ldots 22$

9. Electron Diffraction Data from Calcium Uranium Oxide Phase ......... 28

10. Electron Diffraction Data from Uranium Silicate Phase $\ldots \ldots \ldots \ldots . \ldots . . . .32$

11. Electron Diffraction Data from Uranium Silicide $\ldots \ldots \ldots \ldots \ldots \ldots \ldots$

12. Electron Diffraction Data from Uranium Phosphite $\ldots \ldots \ldots \ldots \ldots \ldots$

13. Crystallographic Data for $\alpha$ - and $\beta-\left[\mathrm{U}\left(\mathrm{PO}_{3}\right)_{4}\right] \ldots \ldots \ldots \ldots \ldots \ldots \ldots$

14. Distribution of Uranium Phases in Dithionite/Tiron-Treated

Soil Samples . . . . . . . . . . . . . . . . . . . . . . . . . . 39

vii 


\title{
ANALYTICAL ELECTRON MICROSCOPY CHARACTERIZATION OF URANIUM-CONTAMINATED SOILS FROM THE FERNALD SITE
}

FY 1993 REPORT

by

E. C. Buck, J. C. Cunnane, N. R. Brown, and N. L. Dietz

\begin{abstract}
A combination of optical microscopy, scanning electron microscopy with backscattered electron detection (SEM/BSE), and analytical electron microscopy (AEM) is being used to determine the nature of uranium in soils from the Fernald Environmental Management Project. The information gained from these studies is being used to develop and test remediation technologies. Investigations using SEM have shown that uranium is contained within particles that are typically 1 to $100 \mu \mathrm{m}$ in diameter. Further analysis with AEM has shown that these uranium-rich regions are made up of discrete uranium-bearing phases. The distribution of these uranium phases was found to be inhomogeneous at the microscopic level.
\end{abstract}

\section{SUMMARY}

A combination of optical microscopy, scanning electron microscopy with backscattered electron detection (SEM/BSE), and analytical electron microscopy (AEM) is being used to determine the nature of uranium in soils from the Fernald Environmental Management Project (FEMP), as part of the Uranium in Soils Integrated Demonstration (ID) program. The information gained from these studies is being used to develop and test remediation technologies.

As part of this work, a method has been developed for preparing transmission electron microscopy (TEM) thin sections by ultramicrotomy. This method has allowed direct comparison between SEM and TEM images. The soil samples examined were untreated soils from several sampling locations in Operable Unit 3 (SP4, SP5, and SP2-3) and treated soil from the incinerator area (A14). Work is still in progress on samples of treated soil from the storage pad area in Operable Unit 3 (B16).

Uranium-bearing phases identified include uranium adsorbed onto iron oxides, uranium silicates, uranium phosphates (autunites), uranium oxides $\left(\mathrm{UO}_{2+\mathrm{x}}\right)$, calcium uranium oxide, and uranium contained within a calcium fluorite phase. Results suggest that the majority of these phases contained uranium in the (VI) oxidation state; however, large $(>10 \mu \mathrm{m})$ particles of [U(IV)] phases have also been identified, including uranium metaphosphate $\left.\left[\mathrm{U}^{\left(\mathrm{PO}_{3}\right.}\right)_{4}\right]$, 
uranium silicide $\left(\mathrm{USi}_{2-\mathrm{x}}\right)$ and uranium oxides $\left(\mathrm{UO}_{2}\right)$. No detectable uranium was found to be associated with the major phyllosilicates (chlorite and mica) in the soil.

Analysis by SEM/EDS of A14 soil samples washed with a carbonate solution demonstrated that $>65 \%$ of the residual uranium in the soils was in a uranium metaphosphate $\left[\mathrm{U}\left(\mathrm{PO}_{3}\right)_{4}\right]$ form and around $20 \%$ as uranium oxide. Examination of A14 soil samples treated with carbonate and citrate suggests that the washing process is unable to deal with ceramiclike uranium phosphite phases and uranium oxide particles.

Our results suggest that dithionite/Tiron treatment does not selectively remove any particular species. In addition, SEM and AEM observations showed that the A14 samples provided by Los Alamos National Laboratory and Oak Ridge National Laboratory were dissimilar, which may be due to heterogeneity in the original A14 sample.

Analytical electron microscopy was used to identify specific uranium-bearing phases in FEMP soils. The information obtained complements that obtained by other characterization techniques, such as SEM, X-ray diffraction, and X-ray absorption spectroscopy (XAS). The AEM results, which were in agreement with XAS data, suggest that the majority of the uranium was in U(VI) phases. Although with AEM it is difficult to determine the amount of the various uranium oxidation states in bulk soil samples, phases were identified which complemented the XAS measurements used to characterize bulk soil.

Electron beam characterization of treated and untreated site soil samples, combined with other techniques that are being used in the Uranium in Soils ID program, provides a scientifically defensible basis for evaluating and optimizing the performance of candidate cleanup procedures. It also supports efficient development of remediation technologies by providing knowledge of (a) the nature of the uranium contamination remaining in soils after treatment and (b) the reason why a particular technology works or does not work. 


\section{INTRODUCTION}

The Feed Materials Production Center, now known as the Fernald Environmental Management Project (FEMP), became contaminated with radioactive and toxic wastes generated during defense-related uranium processing operations. The U.S. Department of Energy (DOE) suspended production there in 1986 and is now involved in remediating the site. A remediation technology project begins with a characterization of the nature and distribution of the contamination; then, once the characterization is complete, chemical and physical separation technologies are developed. Development of remediation technologies based on physical and chemical separation requires knowledge of the nature and distribution of uranium in the soil.

An integrated demonstration (ID) site for remediation of uranium-contaminated soils has been established by the DOE Office of Technology Development. The FEMP site, in Fernald, Ohio, was selected as the facility to be used for field demonstration. The ID Characterization Task Group is currently involved in obtaining data on the nature of uranium contamination in the site soil. The task entitled "Analytical Electron Microscopy Examination of Fernald Soils" has involved a detailed study of the uranium-bearing particles and phases present in the soils. The objective of this investigation is to provide information on the uranium phases. This information will support development of remediation procedures by providing a basis for understanding what has, and has not, been removed from the soils in laboratory and pilot testing of remediation options.

This report presents the results of (1) analytical electron microscopy (AEM) characterization studies of untreated soil samples (SP4, SP2-3, and SP5) and (2) AEM studies of treated soil samples (A14 and B16). The latter studies were performed to support soil washing investigations. This document describes the characterization of uranium-bearing soil fractions, including both treated and untreated site soils. The objectives of this year's effort have been to (a) demonstrate the use of a combination of optical microscopy, SEM using backscattered electron detection (BSE), and AEM, as a coherent methodology to provide representative characterization data on the uranium-bearing phases within the contaminated soil, and (b) to identify discrete uranium phases found in both treated and untreated samples.

\section{A. Analytical Electron Microscopy}

Analytical electron microscopy is a combination of transmission electron microscopy (TEM), energy dispersive X-ray spectroscopy (EDS), electron energy loss spectroscopy (EELS), selected area electron diffraction (SAED), and convergent beam electron diffraction (CBED). Point-to-point resolution for images obtained with the TEM approaches $0.3 \mathrm{~nm}$. The smallest region that can be investigated by using electron diffraction, energy dispersive spectroscopy, and electron energy loss spectroscopy is about $20 \mathrm{~nm}$. At the Chemical Technology Division of Argonne National Laboratory, the AEM facilities include two energy dispersive X-ray detectors and a parallel electron energy loss spectrometer (PEELS). Electron energy loss spectroscopy is capable of detecting helium and higher atomic number elements, as well as detecting rare earth and transuranic elements at low levels $(\sim 50 \mathrm{ppm})$. Analytical 
electron microscopy is a very powerful tool for investigating soils contaminated with particulate uranium-bearing phases.

When high-energy electrons pass through a solid, they interact strongly through a number of inelastic and elastic processes, which allow us to obtain useful structural and compositional data on nanometer-sized particulates.

In these studies, the same soil sample has been examined by optical microscopy, scanning electron microscopy (SEM), and AEM, which has required the development of a procedure to permit the same soil particle to be tracked through each step. Because AEM studies require that the samples be extremely thin $(<\sim 70 \mathrm{~nm})$, ultramicrotomy is used to obtain thin sections of soil particles embedded in an epoxy resin. Several embedding resins were tried to find the one best suited for conducting SEM examination and for making soil thin sections for AEM.

\section{B. Characterization Studies at Fernald Environmental Management Project}

To characterize the nature of uranium contamination in soils in accordance with the U.S. Environmental Protection Agency's protocol for Tier I and Tier II characterization operations (EPA, 1992), a combination of techniques is required. The objectives are to determine the distribution of contamination by size fraction (Tier I) and to determine the nature of the uranium phases and provide data on the distribution of the uranium contamination between these phases (Tier II).

The Characterization Task Group has used a number of techniques to analyze Fernald soils. Only by using these techniques in combination can a fully useful description of the contamination be obtained. X-ray absorption spectroscopy (XAS) can provide quantitative estimates on the amounts of particular uranium oxidation states. Analytical electron microscopy gives complete phase identifications, even if the phase has not been described in the literature. The sensitivity of AEM is greater than that of X-ray diffraction (XRD) and SEM, though these other techniques provide data at a macroscopic level. The following paragraphs summarize the results of previous Fernald characterization studies. In these studies, samples from the following untreated sites were used: storage pads SP4, SP2-3, SP5, and SP9. In addition, samples have been analyzed from the following treated sites: incinerator site A14 and storage pad B16.

Uranium phases in Fernald site soils have been characterized by XRD and SEM analysis by Lee and Marsh (LEE, 1992). These techniques tend to concentrate on micrometer-sized particles. Uranium has been determined to occur in a particulate form, predominantly in the sand and silt fraction of the soil, but there were also significant amounts of uranium in the clay fraction. Scanning electron microscopy analysis of the sand fraction of the A14 soil showed that there was a wide variety of mineral sizes and shapes, with quartz being the dominant fraction. These aggregates contained uranium particles, as well as other heavy metals. Uranium occurred as microfracture-filling minerals in the aggregate. Uraniumrich particles contained calcium, silicon, and phosphorus. Cerium phosphate was also observed. In the silt fraction of the B16 soil, uranium particles were either composed entirely 
of uranium or coexisted with calcium and/or silicon. Both soils were dominated by carbonate (calcite and dolomite) and quartz minerals. An XAS study has been performed by Morris et al. (MORRIS, 1992) to probe the structure at the molecular level. On the basis of XAS data from bulk samples, the majority of the uranium (i.e., $>80-90 \%$ ) in unprocessed soils (SP4, SP5, SP2-3, and SP9) existed in the hexavalent state. The Fourier transform of the $\mathrm{X}$-ray absorption near-edge structure (XANES) (providing a radial distribution function) and the position of the uranium $L_{\text {III }}$ edge $(\sim 17,162 \mathrm{eV})$ were used to determine both uranium oxidation states and the relative abundance of each uranium oxidation state (CHISHOLM, 1992). The hexavalent oxidation state is considered to be advantageous for remediation, as U(VI) species are more soluble than other uranium species. Bertsch et al. (BERTSCH, 1993) have used a micrometer-sized $(50-300 \mu \mathrm{m}) \mathrm{X}$-ray probe and proved that the uranium was present in particulate form. Efforts by both Morris et al. and Bertsch et al. to use XAS to identify specific uranium minerals (by examining the fingerprint region at energies above the uranium $\mathrm{L}_{\mathrm{III}}$ edge) have not been successful. X-ray fluorescence spectra collected by Bertsch et al. indicated that much of the uranium was associated with iron and manganese. Optical luminescence investigations by Morris et al. showed that uranium phases in these Fernald soils exhibited the characteristic structured yellow-green emission from the uranyl $\left(\mathrm{UO}_{2}{ }^{2+}\right)$ moiety.

Analytical electron microscopy studies conducted by Buck et al. (BUCK, 1993a) on sample SP2-3 and SP9 have shown that uranium is contained in discrete uranium-bearing phases. These phases cannot be identified positively by SEM, XAS, or luminescence techniques. In the AEM studies, uranium was found to exist in uranium oxides and uranium phosphates. Uranium was also found to be adsorbed onto the surface of iron oxide/hydroxide, and some was contained within a calcium fluoride phase (fluorite). Although it was determined that most uranium was located in the clay fraction of the site soils (LEE, 1992), AEM studies did not show uranium to be associated with specific clay minerals. Uranium was in particulate form as discrete phases. The AEM techniques of EDS and EELS (which has superior resolution and detection limits over EDS) were unable to detect uranium in clay minerals in the clay fraction.

\section{Uranium Weathering}

To characterize soil samples, it is necessary to know how the uranium released during the processing operations at the site has begun to interact with the local environment. Such interactions, termed "weathering," will affect the transportability of uranium in the groundwater system. Uranium weathering transforms the primary uranium-bearing phases into secondary minerals or causes the uranium to be incorporated into other phases. At the uranium deposit at Koongarra, Australia, studies have been conducted to understand the behavior of uranium in the environment (EDGHILL, 1991). There, weathering of the rock resulted in uranium following the distribution patterns of iron oxide/oxyhydroxides. Penetration of iron, uranium, and oxidizing conditions occurred preferentially along chlorite veins, where the rock structure may have been weak. Biotite was also enriched with uranium during alteration, suggesting that uranium closely followed the weathering fronts. Solution extraction procedures confirmed the findings of electron microscopy investigations at Koongarra, demonstrating the value of microscopy in characterizing the distribution of uranium in the 
environment. Examples of weathering of uraninite $\left(\mathrm{UO}_{2}\right)$ have also been described in studies related to the disposal of spent fuel from nuclear reactors. The sequence of secondary phase formation was remarkably similar in laboratory tests (WRONKIEWICZ, 1992) and natural settings (FINCH, 1992). These results suggest that weathering may occur at the Fernald site.

\section{Soil Description}

A complete description of soils at Fernald has been given by Lee (LEE, 1992). The storage pad soil contains $46 \%$ quartz, $15 \%$ calcite, $19 \%$ dolomite, and $20 \%$ clay, and the incinerator soil is $65 \%$ quartz, $20 \%$ calcite, $2 \%$ dolomite, and $13 \%$ clay. The background soils (Hinshaw and Fincastle) do not contain carbonates.

\section{Source of Uranium Contamination in Fernald Soils}

At FEMP, the soil generally was contaminated by three sources: airborne uranium dust particles, aqueous uranium wastes, and solid uranium product spills (LEE, 1992). In this investigation, the soils studied were taken from the following sampling areas: (1) SP4 (Plant $1 /$ Storage Pad Area), where the contamination resulted mainly from uranium product spills; (2) A14 (vicinity of the incinerator plant); (3) SP5 (decontamination area pad); and (4) SP2-3 (Plant $2 / 3$ area). Size fractionation has been performed to determine the fraction with the highest uranium concentration. The greatest uranium contamination did not always occur with the clay size fraction. In SP5, the highest uranium concentration was associated with gravel-sized slag materials. In SP4 and SP2-3, the highest contamination was in the sand fraction (0.053 to $2 \mathrm{~mm})$.

The A14 soil samples that were examined had been subjected to one of three treatment procedures: gravimetric separation, performed by D. Chaiko of Argonne National Laboratory (ANL) (CHAIKO, 1993); citrate and carbonate washing cycles, performed by C. Francis of Oak Ridge National Laboratory (ORNL); and a dithionite/ Tiron extraction procedure, performed by J. Brainard of Los Alamos National Laboratory (LANL).

\section{Soil Components}

The major components of the contaminated soils have been identified by SEM and XRD as various clays and quartz. These examinations also revealed that uranium inclusions were associated with the clay fraction of the soil, but a unique description of the phases was not provided (LEE, 1992). 


\section{EXPERIMENTAL METHODS AND DEVELOPMENT}

Gram quantities of the SP4, SP2-3, and SP5 samples were provided by Dr. S. Y. Lee of ORNL. The samples obtained by ANL were taken from core samples that were removed from selected locations in operable units, while A14 and B16 soil samples, which were provided in milligram quantity, were isolated after soil processing. In some samples we were provided with the uranium concentrate, while in others we were provided with the "cleaned" soil sample. For each site soil sample, it was essential that a representative portion be isolated for analysis; therefore, a combination of optical microscopy, SEM, and AEM was used.

\section{A. Instrumental Methods}

Uranium-bearing phases were isolated by using micromanipulation techniques assisted by a Zeiss polarizing light microscope, other optical microscopes equipped with ultraviolet light sources, and an SEM (TOPCON ISI-80) that was equipped with a Robinson BSE detector. Thin sections for TEM analysis were produced with an ultramicrotome (ReichertJung Ultracut E). The thin sections were collected on slotted, 150-mesh, carbon-coated copper grids.

Analytical electron microscopy was performed using a TEM (JEOL 2000FXII), operated at $200 \mathrm{kV}$. Compositional analyses were carried out by using two EDS detectors (an ultrathin window light-element detector and high take-off angle beryllium window detector from Noran Instruments) and a parallel EELS system (Gatan 666).

Phases were analyzed by using EDS, EELS, SAED, and CBED. Electron diffraction data from uranium-bearing phases were compared to XRD data from the literature to assist in identifications. Because of the small size of many of the phases present in the soils, microdiffraction and CBED were often used to obtain structural data. Occasionally, a Kikuchi map was constructed of a phase of interest, and the crystal structure of the phase was determined uniquely. As the particles were often less than a micrometer in size, tilting between major zone axes was accomplished in dark-field mode.

The camera lengths were determined by using a polycrystalline aluminum standard. Compositions were calculated by using experimentally determined $\mathrm{k}$-factors from mineral and glass thin-film standards obtained on the JEOL 2000FXII by the Cliff-Lorimer method (CLIFF, 1975).

\section{B. Ultramicrotomy}

An important aspect of the overall analysis was the development of a technique to follow a unique particle through each step in the analysis procedure. The main focus of the techniques was on the use of ultramicrotomy in preparing TEM sections (BUCK, 1993b).

Thin-sectioning of isolated small particulates for TEM by ultramicrotomy is well described in the literature (HAYAT, 1989; KAY, 1965). Thin sections of soil constituents 
have been prepared using microtomy, but the technique has seen limited use in gross soil studies. Ghabru et al. (GHABRU, 1990) have carried out high-resolution studies of clay minerals by impregnating soils with Spurr's resin and then ultramicrotoming the samples. In studies where a representative sample of the bulk is required, it is necessary to show that one is observing the same regions in the SEM and in the TEM. This has usually been difficult to accomplish, as it requires producing an intact section along a precise direction and over a specific area. Comparison of SEM and TEM images allows greater confidence in determining that the uranium-bearing phases examined are not just peculiarities, but true representations of the major uranium-bearing phases in the soil.

To provide a representative characterization of uranium phases distributed in soil, a relatively large number of particles must be examined. This was achieved by mounting particles for SEM and examining polished cross sections with SEM/BSE. Because the objective was to use an embedding resin that would allow a uranium-containing particle to be thin-sectioned directly from the SEM mount, it was imperative to use a resin with optimum infiltration and sectioning properties. Particles were either mounted in inverted BEEM ${ }^{\mathrm{TM}}$ capsules (for small quantities) or in a suitable flat mold (for large quantities). A flat, shallow mold has an advantage because it can be mounted in either the light microscope or the SEM. This approach allowed closer correlation between the optical microscopy images and the SEM/BSE images. Selected uranium-bearing particles were identified in the SEM on the basis of density, morphology, and compositional distinctions. Micrographs of regions containing uranium-bearing phases were taken and annotated, so that particles of interest could be examined in the polarizing optical microscope and used for TEM studies. Particles of interest in the flat molds were isolated for ultramicrotomy by scribing the resin around the particle and gluing this piece onto a sectioning block stub. When the particles were closely spaced in the inverted BEEM capsules, it was possible to shape two regions on the block face for simultaneous thin sectioning.

Ultramicrotomy of soil particles is the most appropriate means of viewing the undisturbed spatial relationship of soil components. Because the spatial relationship of uranium phases within the larger particles was well preserved, more uranium-containing areas could be isolated in a given field of view. The increased section quality made it possible to produce completely intact sections that were thinner than sections obtained with epoxy and acrylic resins. Because of these improvements, the uranium phases identified in the TEM could be correlated with the corresponding areas in the SEM/BSE image. For example, in Fig. 1, structures from the same uranium-bearing particle can be seen in both the SEM and TEM micrographs. The slight discrepancy in particle morphology between the SEM and TEM images was due to the sectioning process, which occurred over a depth of $\sim 3 \mu \mathrm{m}$; however, the overall structure of the particles was preserved. 


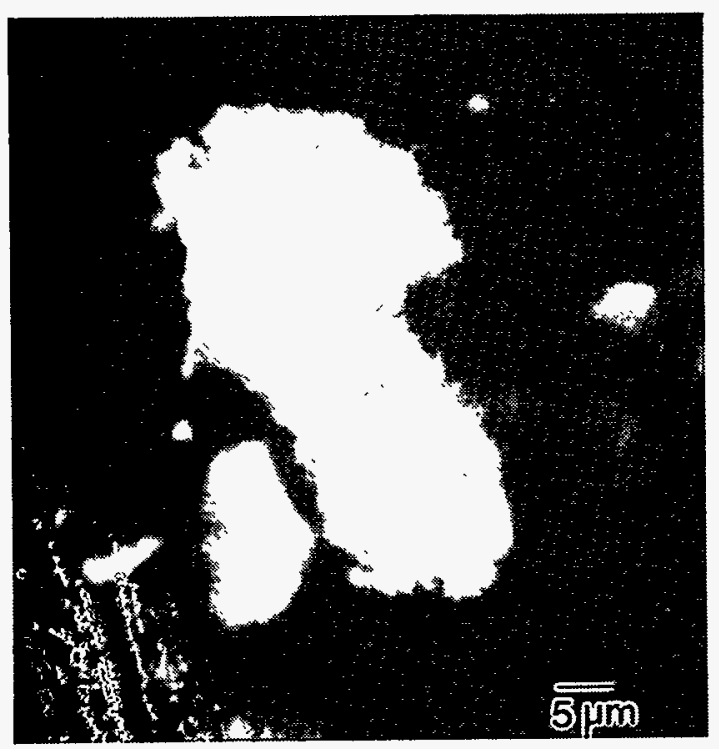

(a)

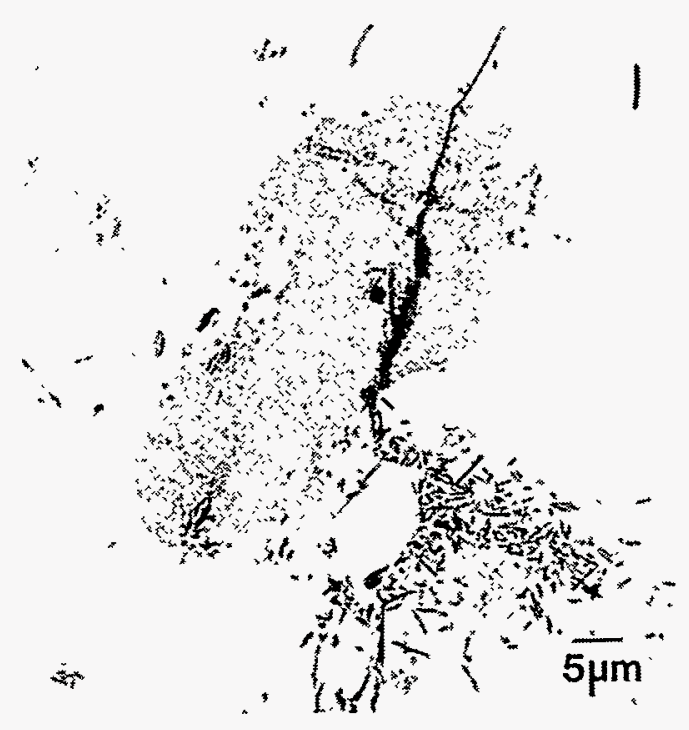

(b)

Fig. 1. Low Magnification Micrographs of a Uranium Phosphate Phase: (a) BSE Image Shows a Collection of Needle-Like Particles, Which Can Also Be Seen in the (b) TEM Image. The uranium-contaminated regions were identified by the white BSE contrast. The particles are similar in shape because the SEM mount has been sectioned nearly parallel to the plane of the paper. 


\section{RESULTS AND DISCUSSION}

Characterization of uranium-bearing phases involved the combination of optical microscopy, SEM, and AEM. Each of these techniques provided vital information that, in many instances, allowed complete characterization of the phases.

\section{A. Optical Microscopy}

Neihesel (NEIHESEL, 1992) has recommended optical microscopy as a major tool for Tier I surveys of contaminated soils, and this procedure has been adopted by the EPA for its soil characterization protocol (EPA, 1992). At the Superfund site at Montclair, AL, soil characterization has been used to determine whether volume reduction techniques are feasible. After the distribution of contamination by particle size was determined, a heavy-mineral fractionation using sodium polytungstate was applied, and the heavy minerals were examined by optical microscopy. The majority of the thorium contamination was in the form of dense monazite particles, indicating that volume reduction would be feasible at this site. Fernald soil samples were examined by optical microscopy, in an effort to correlate uranium phases with specific optical characteristics. The refractive indexes of uranium phases, as well as other phases, are characteristic for identification. Fluorite, zircon, and a few uranium oxide particles were identified, but the images were not clear because the uranium phases were probably too small or not well formed.

Samples were illuminated with ultraviolet radiation to induce luminescence of the uranium-bearing phases. This method is currently being considered by the AEM group at ANL for use in isolating uranium-rich regions. The characteristic yellow-green coloring from an ultraviolet illuminated uranium particle was observed in the SP5 sample.

\section{B. Soil Mineralogy}

While the general mineralogy of the Fernald soil samples (SP2-3, SP4, and SP5) has been described by Lee and Marsh (LEE, 1992), we sought to identify the specific uranium phases in the current samples and to determine the fraction of the uranium associated with the various uranium phases within the clay fraction of the soils. Transmission electron microscopic examination of the soils revealed two major components, quartz and clay. Quartz does not section well, and shattered particles of quartz were often found displaced from their original sites. The clay mineral types in the soil samples were identified as mica and chlorite by SAED, EDS composition data, and the clay morphology. However, specific clay minerals could not be positively identified with the method of analysis used. Unembedded clay minerals exposed to the TEM environment suffer water loss and subsequent collapse of the layers to around $10 \AA$. In addition, variations in focusing and angle of tilt have implications for imaging of clay lattice fringes by altering the apparent size of the spacings (VEBLEN, 1990). Lattice images were taken with an objective aperture that excluded all $h k l$ reflections except the basal (001). Images of clay minerals displaying (001) lattice fringes were taken, along with EDS composition data, to identify mineral types (Fig. 2). The $\sim 10 \AA$ spacings were identified as coming from illite, whereas chlorite was identified by its composition and $\sim 15 \AA \mathrm{c}$-axis spacings. Electron diffraction data from these phases are presented in Tablel. 

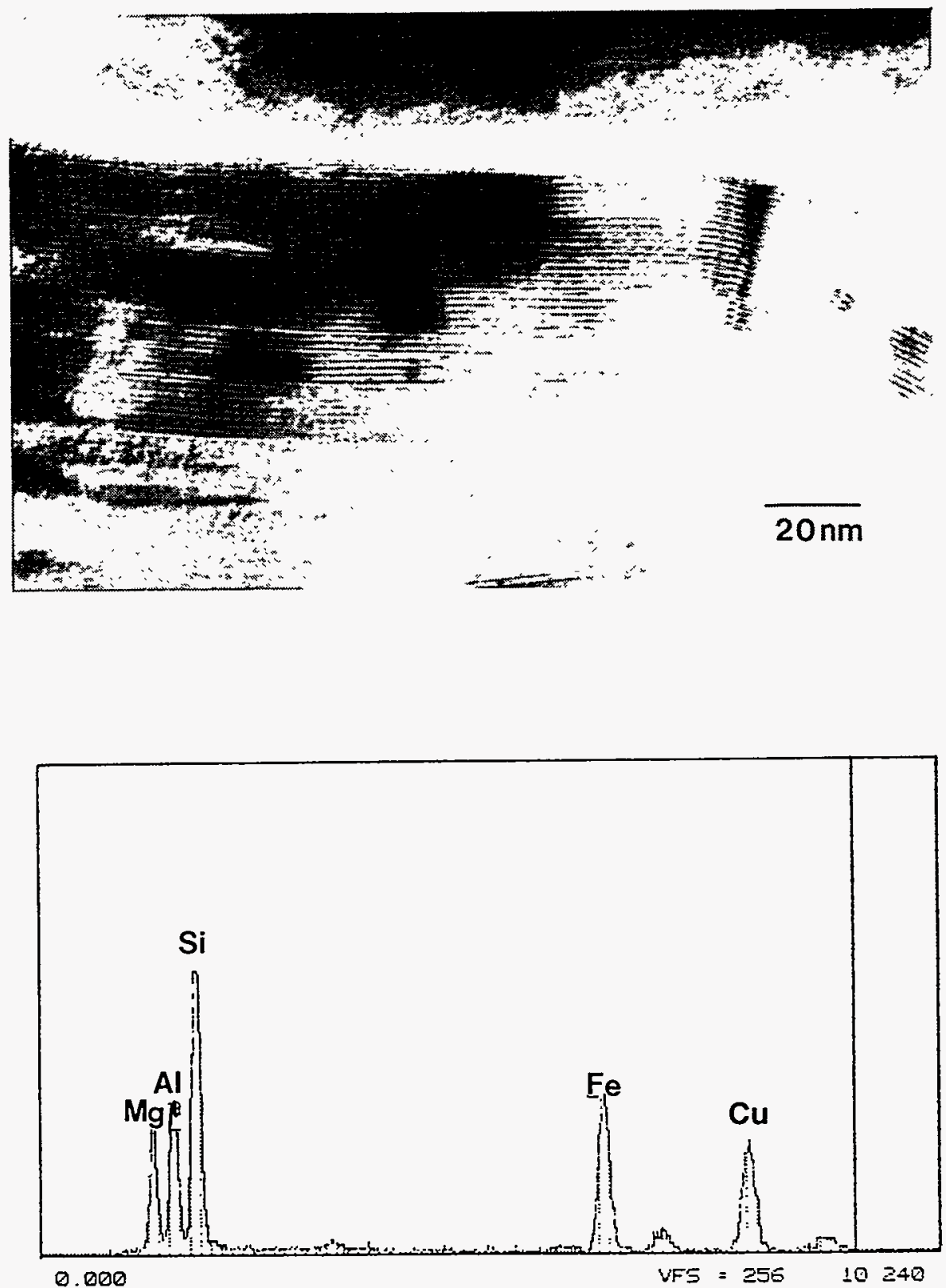

Fig. 2. Lattice Image of Chlorite (Vermiculite) with c-axis Spacings of $\sim 15 \AA$. Ideal composition is $\left[\left(\mathrm{Mg}, \mathrm{Fe}, \mathrm{Al}_{6}\left(\mathrm{Si}_{3.3} \mathrm{Al}_{0.7}\right) \mathrm{O}_{10}(\mathrm{OH})_{8}\right]\right.$; EDS analysis gave $\left[\left(\mathrm{Mg}_{1.65} \mathrm{Fe}_{1.15} \mathrm{Al}_{2.8}\right)\left(\mathrm{Si}_{3.3} \mathrm{Al}_{0.7}\right) \mathrm{O}_{\mathrm{x}}\right]$ 
Table 1. Electron Diffraction Data from Layer Silicate Minerals in SP4 and SP2-3

\begin{tabular}{|c|c|c|c|}
\hline d spacings, $\AA$ & $\pm \AA^{\mathrm{a}}$ & $\begin{array}{c}\text { Mica Group } \\
\text { (JCPDS 29-149), } \AA\end{array}$ & $\mathrm{hkl}$ indices \\
\hline 11.00 & 0.35 & 10.7 & $(001)$ \\
\hline 5.90 & 0.12 & & \\
\hline 5.50 & 0.11 & 5.0 & $(002)$ \\
\hline 4.53 & 0.08 & 4.43 & $(020)$ \\
\hline \multirow[t]{2}{*}{3.67} & 0.06 & 3.66 & - \\
\hline & & & $(112)$ \\
\hline 3.23 & 0.05 & 3.31 & (003) \\
\hline 3.00 & 0.05 & 3.06 & (112) \\
\hline 2.65 & 0.04 & 2.68 & $(023)$ \\
\hline 2.48 & 0.04 & 2.44 & (131) \\
\hline 2.19 & 0.03 & 2.22 & $(220)$ \\
\hline d spacings, $\AA$ & $\pm \AA^{\mathrm{a}}$ & $\begin{array}{c}\text { Chlorite } \\
\text { (JCPDS 16-35), } \AA\end{array}$ & hkl indices \\
\hline 15.29 & 0.66 & 14.4 & (001) \\
\hline 7.65 & 0.19 & 7.15 & $(002)$ \\
\hline 5.10 & 0.10 & 4.79 & (003) \\
\hline 4.65 & 0.08 & 4.63 & $(020),(110)$ \\
\hline 4.48 & 0.08 & & \\
\hline 3.54 & 0.06 & 3.59 & (004) \\
\hline 3.23 & 0.05 & & \\
\hline 3.00 & 0.05 & & \\
\hline 2.95 & 0.04 & 2.87 & $(005)$ \\
\hline \multirow[t]{2}{*}{2.58} & 0.04 & 2.61 & - \\
\hline & & & (202) \\
\hline 2.46 & 0.04 & 2.47 & (203) \\
\hline 2.37 & 0.03 & 2.39 & $(202)$ \\
\hline 2.25 & 0.03 & 2.2 & (203) \\
\hline \multirow[t]{2}{*}{2.01} & 0.03 & 2.01 & 一 \\
\hline & & & $(204)$ \\
\hline 1.88 & 0.03 & 1.9 & (206) \\
\hline 1.75 & 0.02 & 1.758 & $(150),(240)$ \\
\hline 1.54 & 0.02 & 1.548 & $(060)$ \\
\hline 1.51 & 0.02 & 1.515 & $(060)$ \\
\hline 1.39 & 0.02 & & \\
\hline
\end{tabular}

aErrors are based on the inaccuracies associated with the measurement of the spacings and instrument instability. 
Phases found in Fernald soil samples include feldspar (Table 2), rutile, possibly maghemite (iron oxide, $\left[\mathrm{Fe}_{2} \mathrm{O}_{3}\right]$ ), calcium phosphate, calcium carbonate (calcite, $\left[\mathrm{CaCO}_{3}\right]$ ), calcium magnesium carbonate (dolomite), and zircon (which was also identified by optical microscopy).

In Fig. 3, a number of zone axis patterns from a monoclinic feldspar phase are shown. A list of the electron diffraction spacings from feldspar is shown in Table 2. Calcium phosphate phases were often located in the vicinity of some uranium-bearing phases (see Fig. 4). The phase was identified as hydroxyapatite $\left[\mathrm{Ca}_{5}\left(\mathrm{PO}_{4}\right)_{3}(\mathrm{OH})\right]$, on the basis of electron diffraction data (Table 3) and EDS analysis. Iron phosphates, another source for solution phosphate, were found in A14 soil samples. Dolomite $\left[\mathrm{CaMg}\left(\mathrm{CO}_{3}\right)_{2}\right]$, also from the calcite group, was identified by electron diffraction spacings (Table 4), though a symmetry analysis of the phase suggested that it was not hexagonal but rhombohedral, as there were no symmetrical major zone axes (Fig. 5).

Some of these nonuranium-bearing phases, particularly zircon, presented high backscattered contrast. This tended to slow down analysis with SEM/BSE, as these nonuraniumbearing phases had to be ruled out by EDS analysis before proceeding.

The presence of calcite, dolomite, apatite, and iron phosphate as determined by AEM in site soil samples suggests that sources exist for both phosphate and carbonate. These oxygen-containing ligands will strongly complex uranium (uranyl) in solution, leading to the formation of uranium phosphates and carbonates (SANDINO, 1992), though the latter were not observed (probably because of their high solubility).

\section{Identification of Uranium-Bearing Phases}

Analytical electron microscopy revealed at least four major types of phases that contained uranium: calcium, iron oxide, uranium oxide, and uranium phosphate phases. On the basis of the EDS and EELS detection capabilities of the AEM ( 0.1 wt \%), uranium was not observed to be associated with clay phases in the soils. The following describes in detail the AEM analysis of uranium-bearing phases observed in soil samples SP4, SP2-3, SP5, A14, and B16. During FY 1992, an examination of SP4 showed that AEM was applicable for phase identification in the Fernald soils (BUCK, 1993a).

\section{Uranium in Iron Oxides}

Amorphous uranium-bearing iron oxide phases were observed in some regions of the SP2-3 and SP4 samples. This type of uranium phase had a different morphology compared to that of the calcium uranium fluorite phase (BUCK, 1993a). Often it consisted of small particles ( $100 \mathrm{~nm}$ in diameter) that appeared to be strung together into a much larger agglomerate. On occasion, calcium and iron uranium phases were observed in close proximity (i.e., $<1-2 \mu \mathrm{m}$ separation).

The uranium concentration varied considerably, from around 10 to $60 \mathrm{wt} \%$ (Table 5), suggesting that the uranium was adsorbed onto the surfaces of the iron oxide particles. In SP2-3, small uranium phases were observed in the iron oxide phase, though 
Table 2. Electron Diffraction Data from Feldspar Phase in Sample SP4

\begin{tabular}{|c|c|c|}
\hline $\mathrm{d}$ spacings, $\AA$ & $\pm \AA^{\mathrm{a}}$ & Sanadine (JCPDS 25-618), $\AA$ \\
\hline 4.32 & 0.07 & 4.24 \\
\hline 3.72 & 0.06 & 3.79 \\
\hline 3.79 & 0.06 & 6.52 \\
\hline 6.52 & 0.14 & 5.87 \\
\hline 5.95 & 0.12 & 3.33 \\
\hline 3.32 & 0.05 & \\
\hline 2.38 & 0.03 & 6.65 \\
\hline 6.64 & 0.15 & 3.33 \\
\hline 3.38 & 0.05 & 4.24 \\
\hline 4.27 & 0.07 & 3.55 \\
\hline 3.54 & 0.06 & 2.549 \\
\hline 2.56 & 0.04 & \\
\hline
\end{tabular}

${ }^{a}$ Errors are based on the inaccuracies associated with the measurement of the spacings and instrument instability.

Table 3. Electron Diffraction Data from Calcium Phosphate Phase

\begin{tabular}{|c|c|c|}
\hline $\mathrm{d}$ spacings, $\AA$ & $\pm \AA^{\mathrm{a}}$ & Hydroxy apatite (JCPDS 9-432), $\AA$ \\
\hline 8.08 & 0.20 & 8.17 \\
\hline 5.39 & 0.10 & 5.26 \\
\hline 4.13 & 0.07 & 4.07 \\
\hline 3.05 & 0.05 & 3.08 \\
\hline 2.82 & 0.04 & 2.81 \\
\hline 2.76 & 0.04 & 2.78 \\
\hline 2.67 & 0.04 & 2.63 \\
\hline 2.56 & 0.04 & 2.53 \\
\hline 2.29 & 0.03 & 2.30 \\
\hline 2.16 & 0.03 & 2.15 \\
\hline 1.97 & 0.03 & 1.94 \\
\hline 1.82 & 0.03 & 1.81 \\
\hline 1.77 & 0.02 & 1.78 \\
\hline
\end{tabular}

${ }^{a}$ Errors are based on the inaccuracies associated with the measurement of the spacings and instrument instability. 
(a)

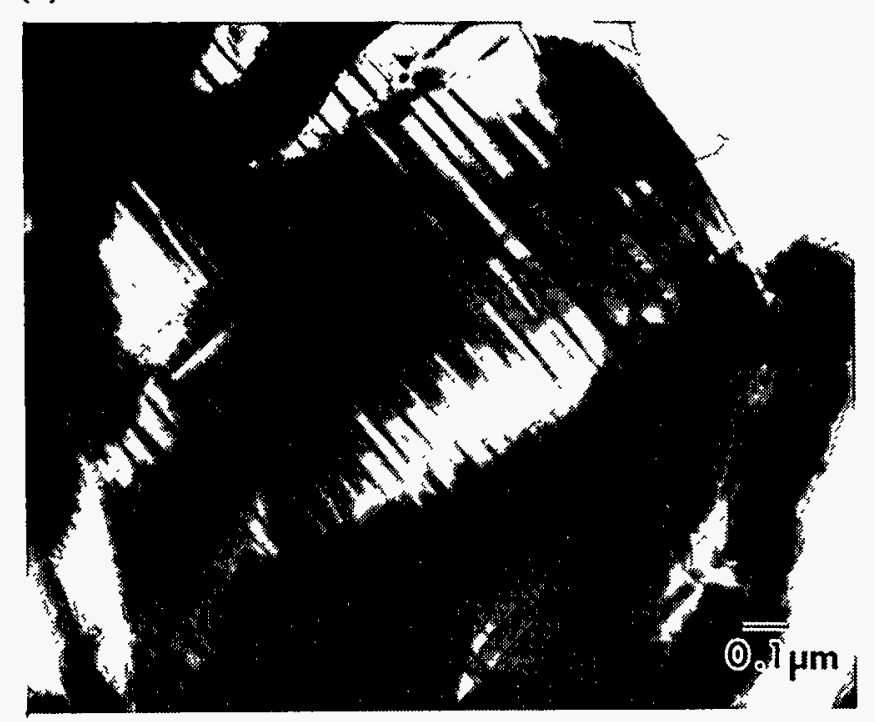

(b)
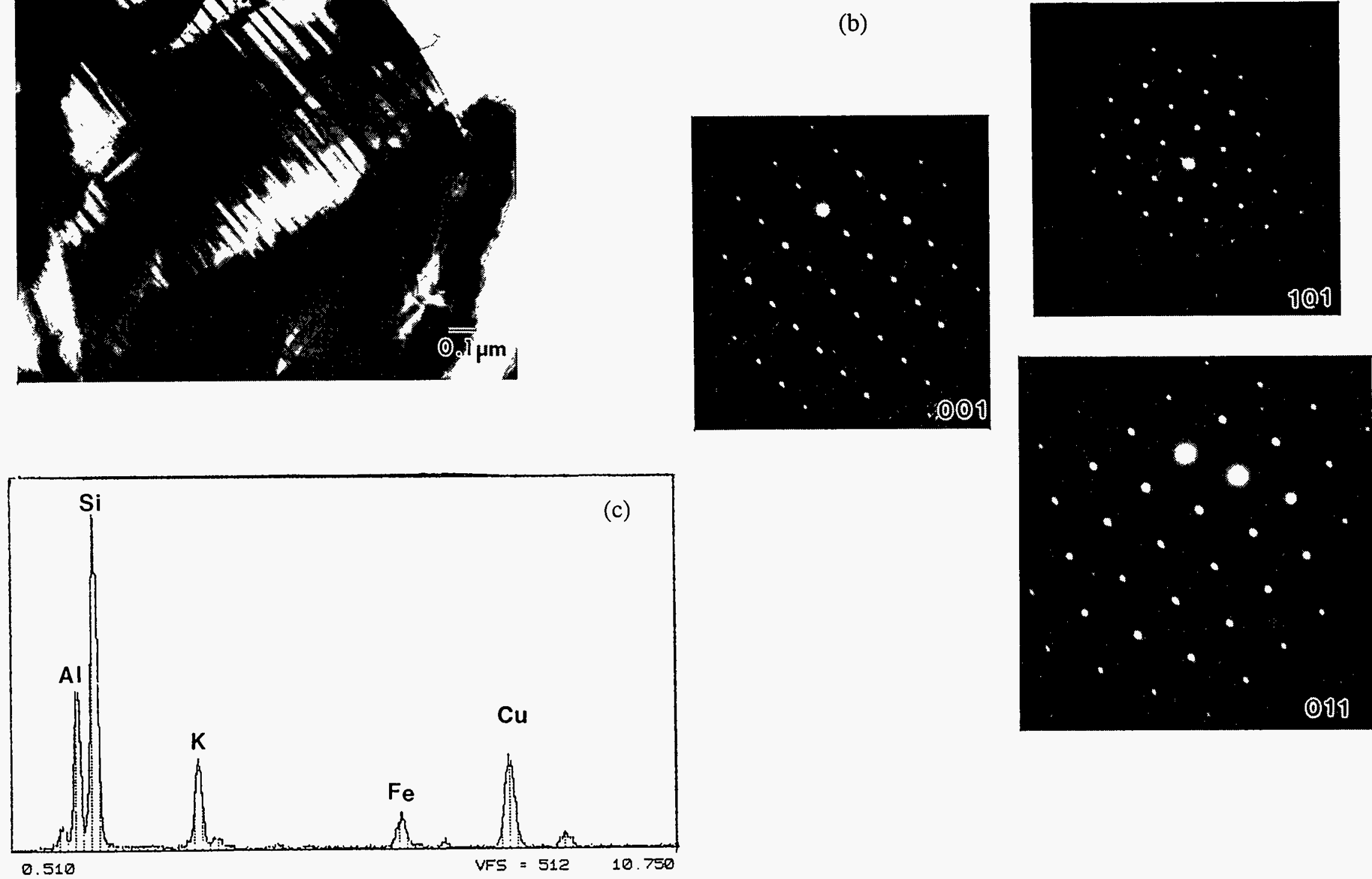

Fig. 3. (a) TEM Image of Potassium Aluminosilicate Phase, along with (b) a Number of Zone Axis Patterns and (c) EDS Analysis 


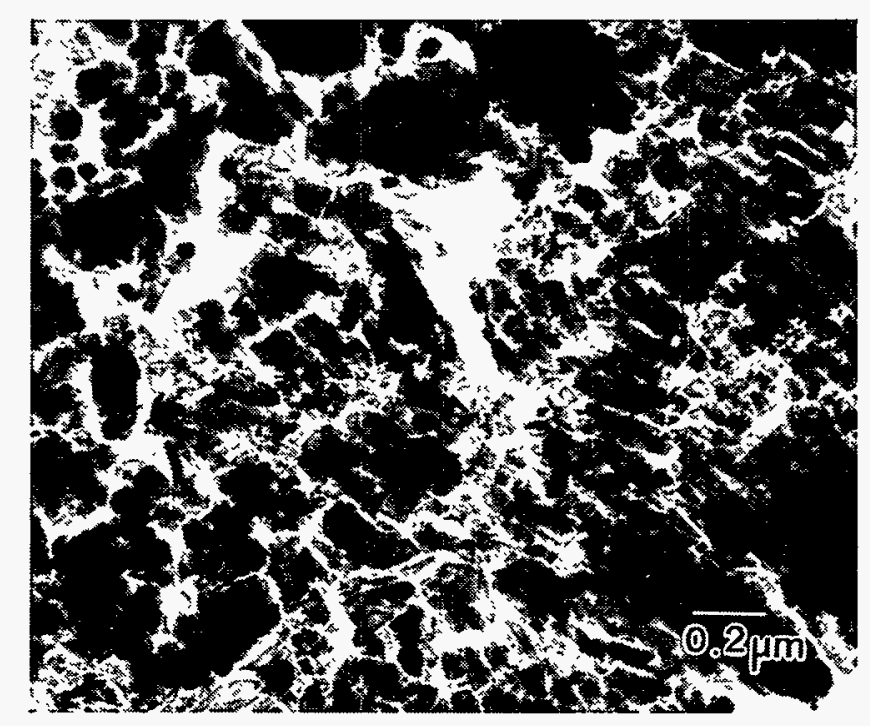

(a)



(b)

Fig. 4. (a) TEM Image of Calcium Phosphate (Apatite) Phase Identified by Electron Diffraction and (b) EDS Analysis 
Table 4. Electron Diffraction Data from Dolomite (Magnesium Calcium Carbonate)

\begin{tabular}{|c|c|}
\hline$d$ spacings, $\AA$ & Dolomite (JCPDS 11-78), $\AA$ \\
\hline 5.34 & \\
\hline 4.06 & 4.03 \\
\hline 3.71 & 3.69 \\
\hline 2.91 & 2.886 \\
\hline 2.69 & 2.67 \\
\hline 2.54 & 2.54 \\
\hline 2.396 & 2.405 \\
\hline 2.197 & 2.192 \\
\hline 2.02 & $2.066 / 2.015$ \\
\hline 1.86 & 1.848 \\
\hline 1.79 & 1.804 \\
\hline
\end{tabular}

Table 5. Results of EDS Analysis of Seven Iron Uranium Oxide Particles

\begin{tabular}{|c|c|}
\hline Uranium (wt\%) & Iron (wt\%) \\
\hline 30.6 & 69.4 \\
\hline 20.1 & 79.9 \\
\hline 33.2 & 66.8 \\
\hline 67.9 & 32.1 \\
\hline 33.0 & 67.0 \\
\hline 87.4 & 12.6 \\
\hline 41.2 & 58.8 \\
\hline
\end{tabular}

these phases were probably phosphates (Fig. 6). Other iron phases were observed in SP2-3. One consisted of spine-like needles, but it did not contain any uranium. Hsi and Langmuir (HSI, 1985) have observed the pH-dependent adsorption of uranyl [U(VI)] on various iron oxides. They found that adsorption was greatest for an amorphous iron oxyhydroxide and for goethite $(\alpha-\mathrm{FeOOH})$ at $\mathrm{pH}>5$. Uranyl adsorption on synthetic and natural hematite was lower than on the other iron oxides.

\section{Uranium Oxide Phases}

Uranium oxide (uraninite) particles were found in the gravimetrically separated portion of A14 soil samples, in the "cleaned" soil fraction of A14 soil samples (which had been washed by citrate and carbonate treatments), and in the untreated samples (SP2-3, SP4, and SP5). 


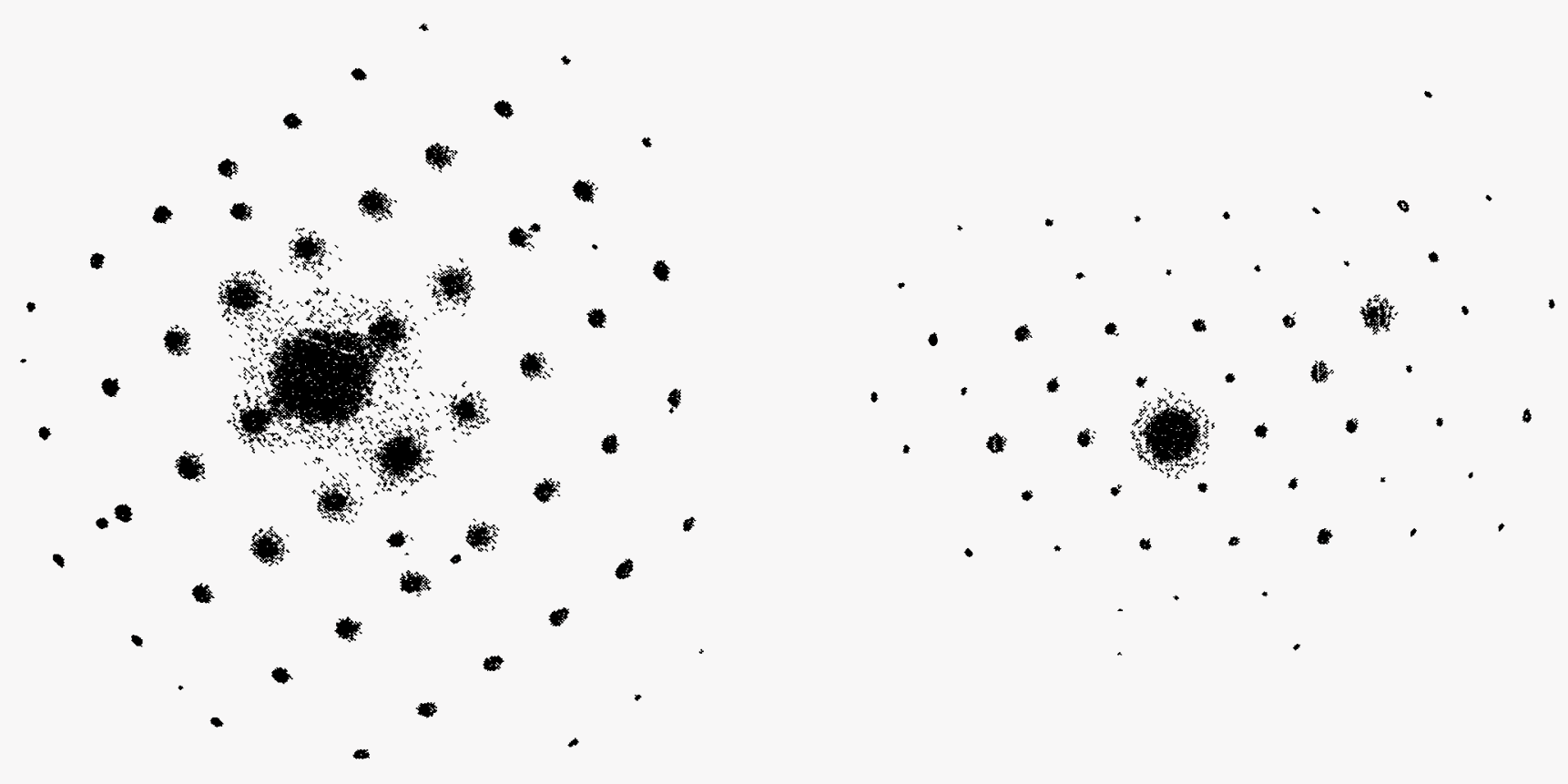

Fig. 5. Electron Diffraction Patterns of the Rhombohedral Calcium Magnesium Carbonate Phase (Dolomite)

The SAED pattern of uranium oxide phases found in SP4, located in the vicinity of the calcium fluoride phase [BUCK, 1993a], matched with that of fluorite $\left(\mathrm{UO}_{2+x}\right) . \mathrm{UO}_{2}$ has not been identified in nature (i.e., in geologic uranium deposits) because it is usually found in an oxidized nonstoichiometric state (FINCH, 1992). The lattice constants for the uraninite unit cell do alter with changes in the $\mathrm{O}: \mathrm{U}$ ratio, as shown in Fig. 7. The change in the unit cell parameters can be detected by XRD but is not readily detectable by TEM (JANECZEK, 1991).

The TEM studies of the oxidized uraninite by Blank and Ronchi indicated that a change in structure between $\mathrm{UO}_{2}$ and $\mathrm{UO}_{2.25}$ is reflected in the electron diffraction patterns (BLANK, 1969). $\mathrm{UO}_{2}$ undergoes oxidation by the incorporation of additional oxygen atoms at the interstitial sites of the cubic fluorite structure (Fig. 8). Each unit cell has four interstitial positions (WILLIS, 1978). If the oxygen atoms enter the lattice in an ordered fashion, the defects produced will be visible both in images and electron diffraction patterns of the phase (SATO, 1965). So far, no evidence of oxygen defect structures has been observed, and only d-spacings matching $\mathrm{UO}_{2}$ have been found.

The SAED pattern of a uranium oxide particle is shown in Fig. 9a, and a CBED pattern demonstrating four-fold symmetry, which is consistent with the cubic fluorite structure, is shown in Fig. 9b. The SAED and CBED patterns matched closely with cubic nonstoichiometric fluorite $\left(\mathrm{UO}_{2+x}\right)$. (See Table 6 for the electron diffraction data.) 
unṇues $\Omega$

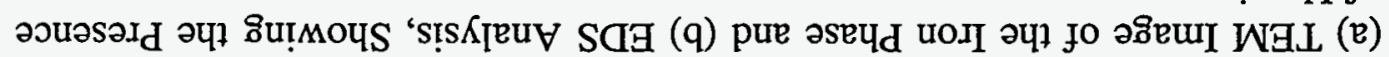
:I!OS E-ZdS pue $\downarrow d S$ u! puno

(q)

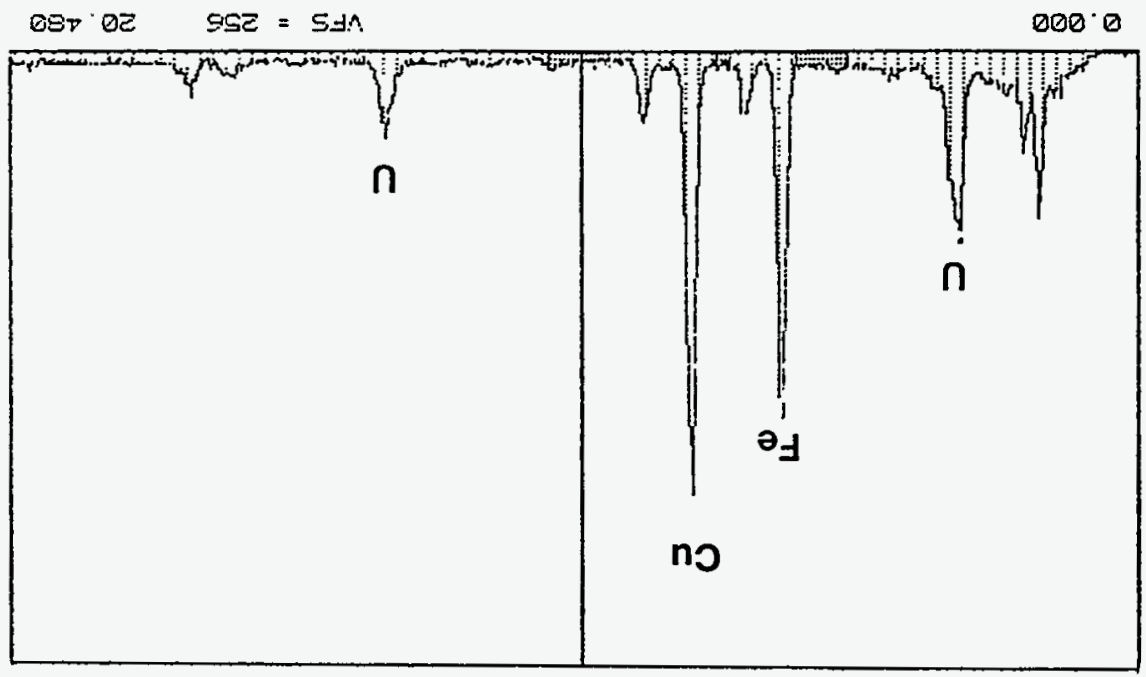

(B)

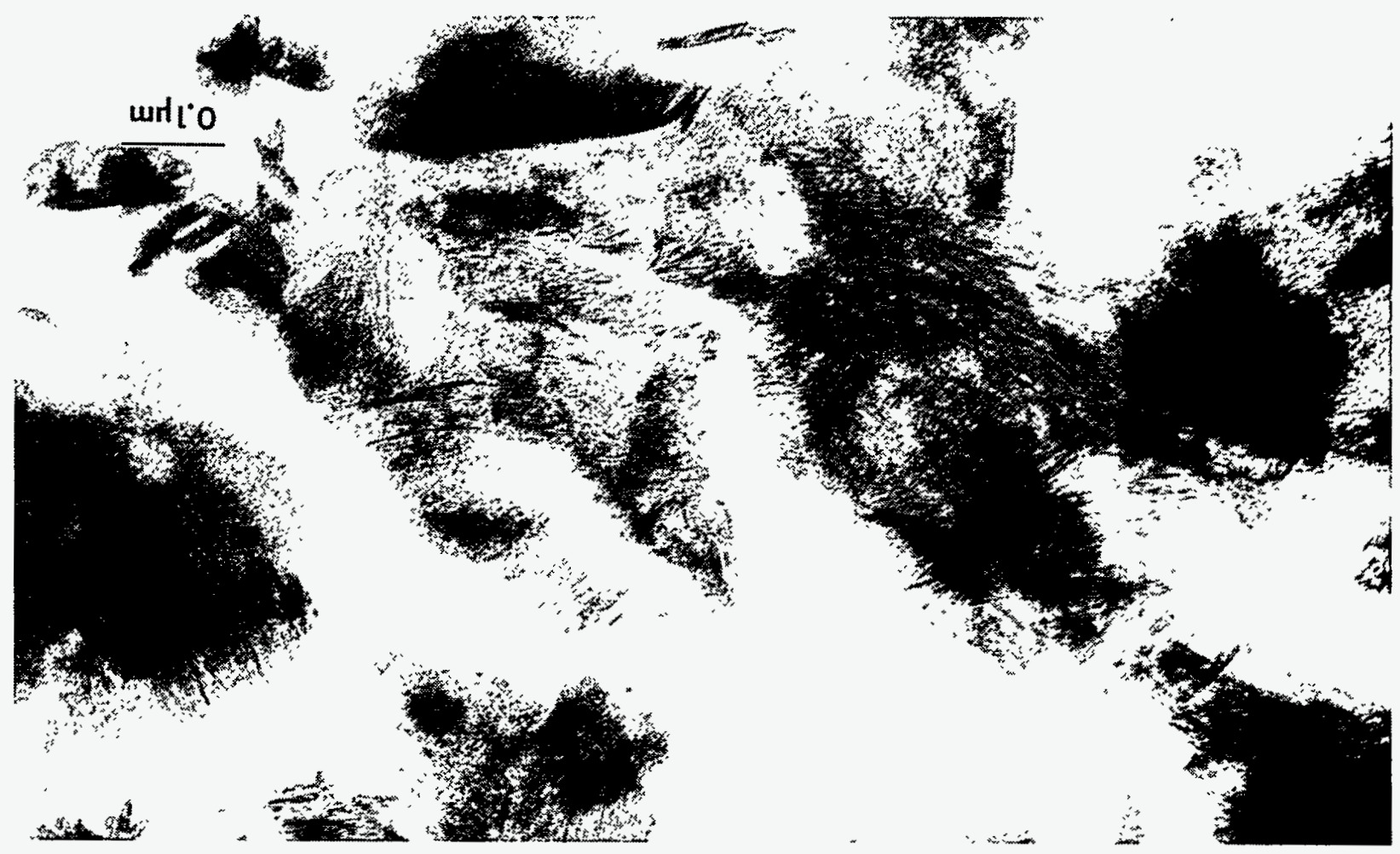




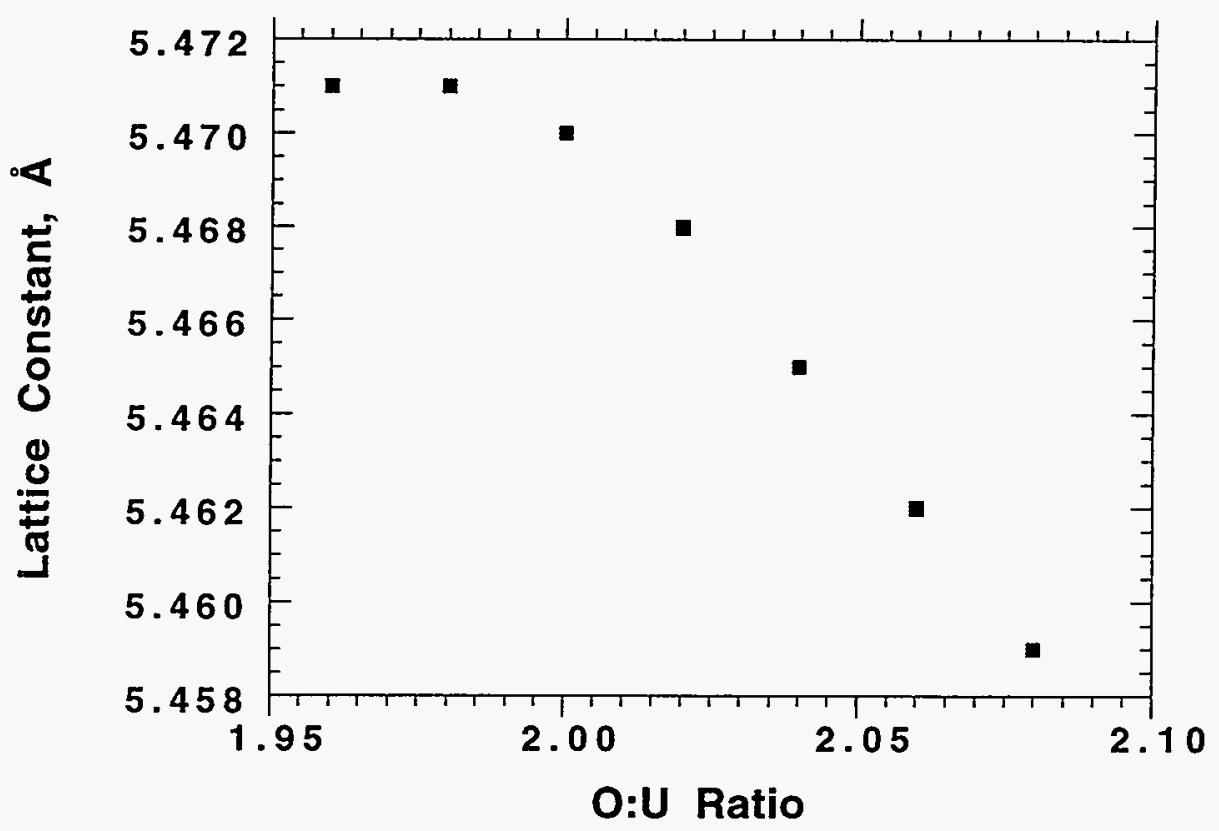

Fig. 7. Variation in Unit Cell Parameter with O:U Ratio in Uranium Oxide (data taken from GMELIN, 1986)

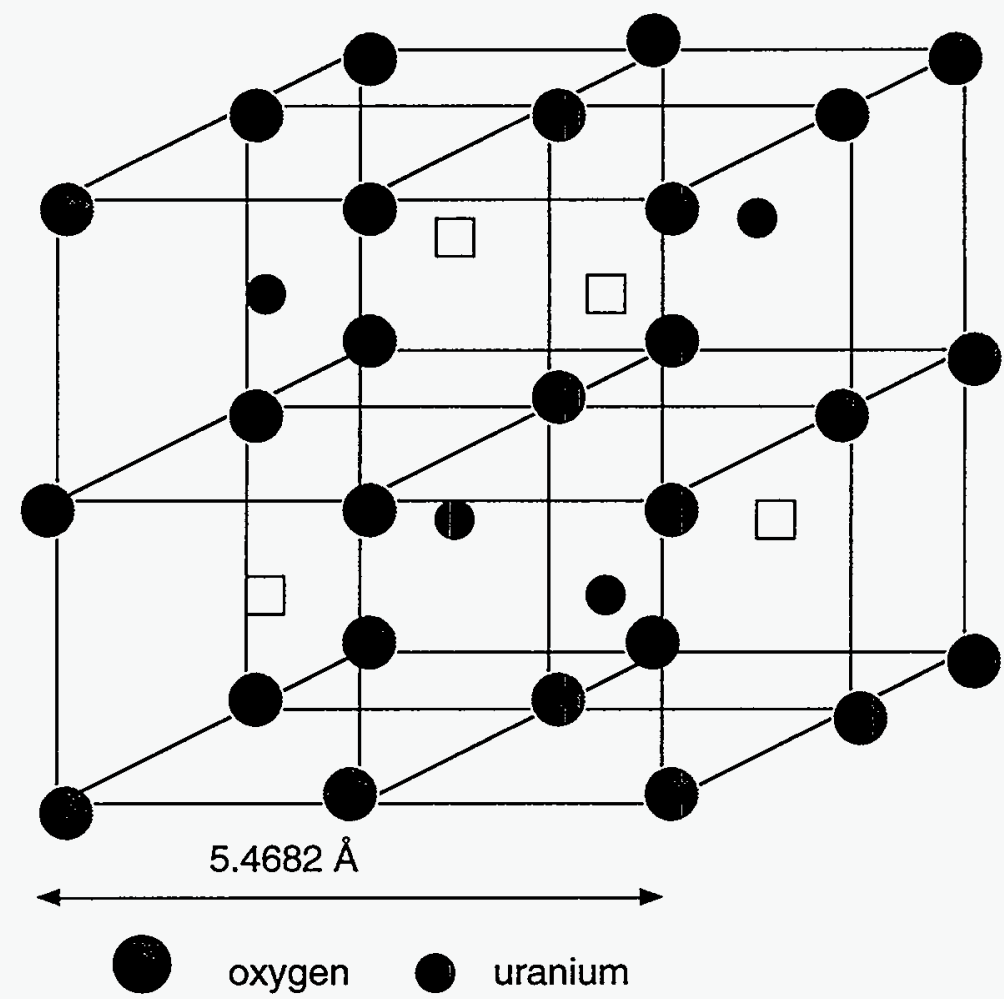

Fig. 8. Displacement of Oxygen Atoms in the $\mathrm{UO}_{2}$ Lattice Following the Incorporation of Additional Oxygen Atoms 


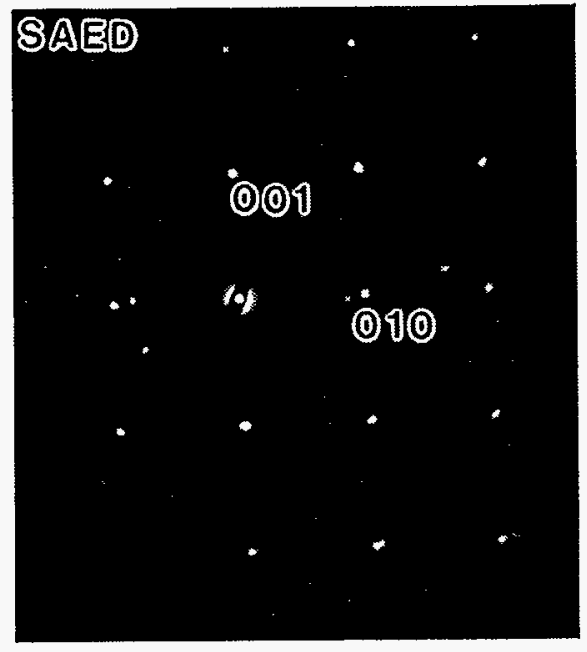

(a)

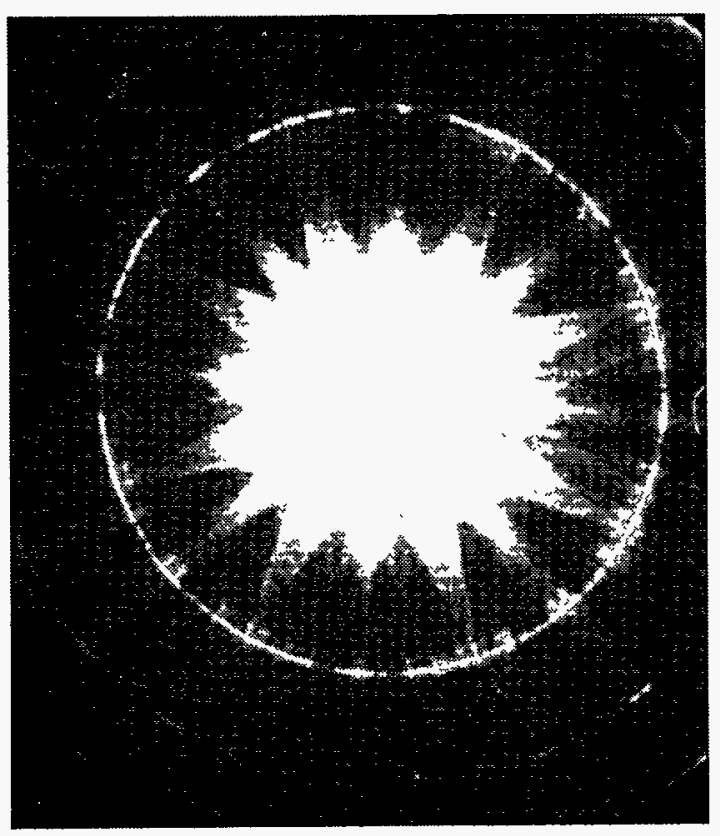

(b)

Fig. 9. (a) SAED Pattern of a Uranium Oxide Taken along the [100] Zone Axis and (b) CBED Pattern

Table 6. Electron Diffraction Data from Uranium Oxide Phase

\begin{tabular}{|c|c|c|c|}
\hline $\mathrm{d}$ spacings, $\AA$ & $\pm \AA^{\mathrm{a}}$ & Uraninite (JCPDS 5-550), $\AA$ & $\mathrm{hkl}$ indices \\
\hline 3.15 & 0.05 & 3.16 & $(111)$ \\
\hline 1.98 & 0.03 & 1.93 & $(220)$ \\
\hline 1.65 & 0.02 & 1.65 & $(311)$ \\
\hline
\end{tabular}

${ }^{a}$ Errors are based on the inaccuracies associated with the measurement of the spacings and instrument instability.

\section{Uranium Phosphate Phase}

A uranium phosphate phase was found in one group of particles in the SP4 soil. The morphology indicates that the phase was crystalline; however, SAED analysis failed to detect any signs of crystallinity. The uranium phosphate particles were elongated, and micrographs appeared to display lattice fringes. A range of possible uranium phosphate phases exists, most of which are so sensitive to electron beams that structural analysis is difficult.

Soil sample SP2-3 possessed many uranium calcium phosphate phases. The distribution of these phosphate phases within the soil suggested that they had formed by 
precipitation from solution. Uranium phosphate crystallites were dispersed amongst chlorite, quartz, and iron oxide phases (Fig. 10). One uranium-bearing phase matched with a phosphuranylite mineral type, $\left[\mathrm{Ca}\left(\mathrm{UO}_{2}\right)_{3}\left(\mathrm{PO}_{4}\right)_{2}(\mathrm{OH})_{2} \cdot 6 \mathrm{H}_{2} \mathrm{O}\right]$ (Table 7), and others matched more closely with autunite and meta-autunite groups (Table 8). The concentration of phosphorus and calcium varied in the phases.

Table 7. Electron Diffraction Data from Uranium Phosphate

\begin{tabular}{|c|c|c|}
\hline $\mathrm{d}$ spacings, $\AA$ & $\pm \AA^{\mathrm{a}}$ & Phosphuranylite (JCPDS 19-898), $\AA$ \\
\hline 9.29 & 0.26 & 8.99 \\
\hline 7.59 & 0.18 & 7.96 \\
\hline 5.76 & 0.12 & 5.86 \\
\hline 4.65 & 0.08 & 4.77 \\
\hline 4.53 & 0.08 & 4.46 \\
\hline 4.04 & 0.07 & 4.00 \\
\hline 3.79 & 0.06 & 3.81 \\
\hline 3.54 & 0.06 & 3.45 \\
\hline 3.39 & 0.05 & 3.40 \\
\hline 3.10 & 0.05 & 3.09 \\
\hline 2.67 & 0.04 & 2.69 \\
\hline 2.31 & 0.03 & 2.23 \\
\hline 2.03 & 0.03 & 2.083 \\
\hline 1.93 & 0.03 & \\
\hline 1.91 & 0.03 & \\
\hline
\end{tabular}

Table 8. Electron Diffraction Data from a Calcium Uranium Phosphate

\begin{tabular}{|c|c|c|}
\hline $\mathrm{d}$ spacings, $\AA$ & $\pm \AA^{\mathrm{a}}$ & Meta-autunite (JCPDS 14-73), $\AA$ \\
\hline 7.15 & 0.17 & 8.17 \\
\hline 3.44 & 0.05 & 3.51 \\
\hline 4.18 & 0.07 & 4.14 \\
\hline 2.70 & 0.04 & 2.72 \\
\hline 2.09 & 0.03 & 2.04 \\
\hline 6.76 & 0.15 & 6.57 \\
\hline 6.19 & 0.13 & \\
\hline 3.03 & 0.05 & 2.96 \\
\hline
\end{tabular}

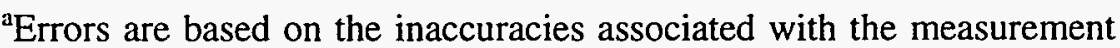
of the spacings and instrument instability. 


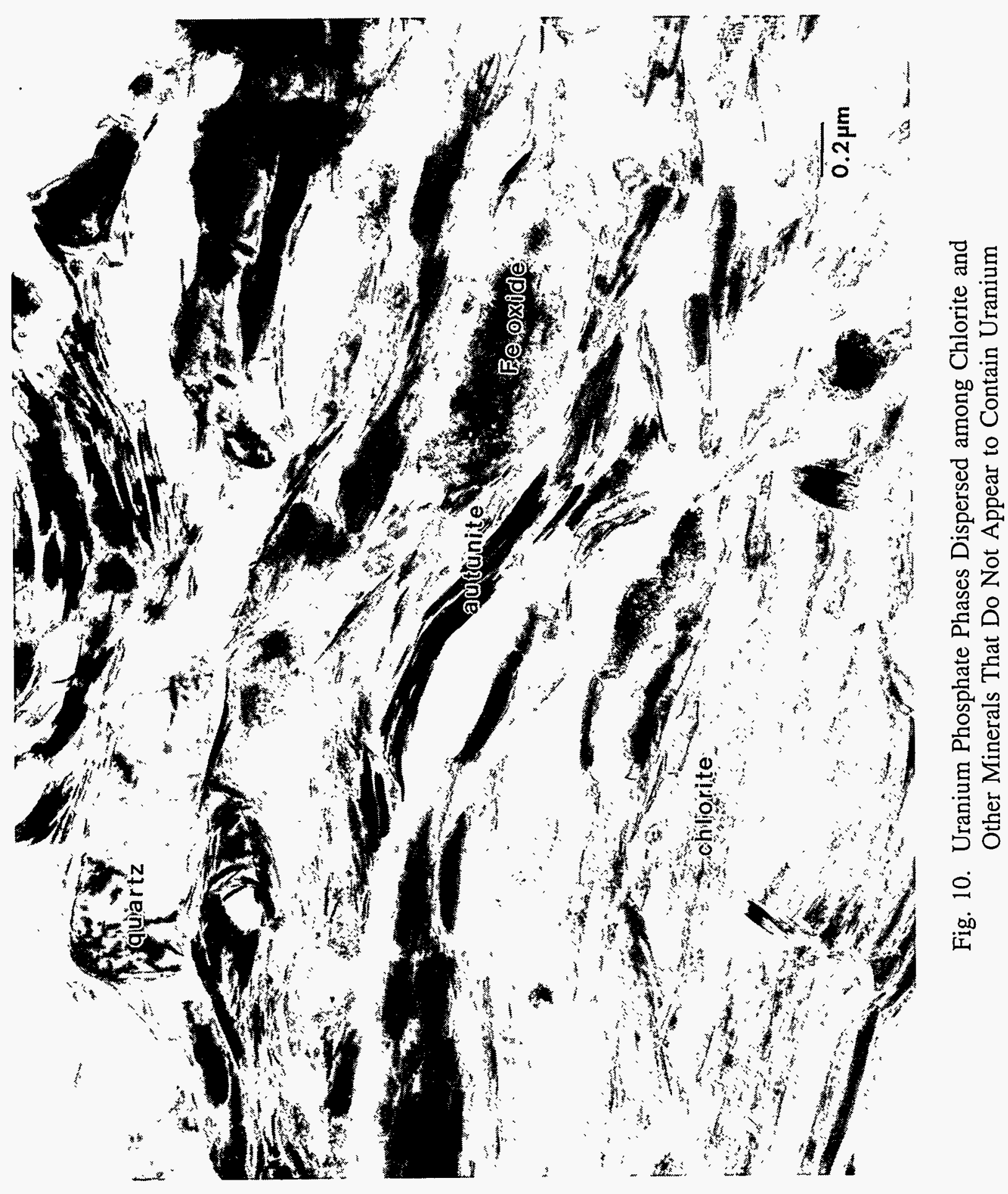


Images from the SEM typically showed large $(>10 \mu \mathrm{m})$ particles containing uranium and phosphorus. In Fig. 11, a partially crystalline uranium-bearing phase in SP2-3 displayed a textured diffraction pattern with two Bragg spots at $11.4 \AA$, which is close to the (002) spacings of several autunites. The presence of calcium phosphate (apatite) in the soil suggests the source of the phosphate that led to the formation of uranium phosphates, a highly insoluble phase. Phosphate ligands, like many oxygen-containing ligands, are strong chelators for the uranyl ion. In spite of the presence of large amounts of solid carbonate phases in site soils, no uranium carbonates were identified. This may have been because uranium phosphates are highly insoluble (SANDINO, 1992).

A similar phase was observed in SP2-3 (Fig. 12). The most commonly obtained pattern was the square SAED pattern, which was taken along the [001] zone axis of the uranium phosphate phase. Mostly tetragonal versions of the autunite phase were observed, but there was an indication of a monoclinic variety in the citrate-treated A14 soil samples. In this sample, the uranium phosphate had a much higher phosphate and calcium signal (see Fig. 13).

The identification of the uranium-bearing phase by SAED has also indicated that the uranium is in the uranyl state [U(VI)]. Autunites are well-known alteration products of uraninite (FINCH, 1992). Alteration of uraninite to a nonstoichiometric oxidized phase can result in the eventual formation of three types of uranium phases: gummite (e.g., schoepite), autunites (uranium phosphates), and uranophanes (e.g., boltwoodite) (JOHNSON, 1988). Uranium emissions from the incinerator may have undergone accelerated weathering, which may account for these types of phases being observed in the vicinity of the plant. In SP4, where some uranium oxide particles were observed, there was no evidence of any alteration of the phase, whereas SP2-3 showed significant redistribution of uranium into phosphate phases.

\section{Calcium Uranium Oxide Phase}

In the untreated SP2-3 soil sample, a calcium uranium oxide phase was observed (Fig. 13). A range of fluorite-like calcium uranium oxide phases display defect structures, and some spacings in the SP2-3 sample matched with those of $\mathrm{Ca}_{y} \mathrm{UO}_{\mathrm{x}}$ type phases (KRASEVEC, 1983). The stability of the phase under the electron beam suggested that the phase was probably not a hydrated mineral, although the electron diffraction data matched with that of the bequerelite group minerals (Table 9). A positive identification could not be made for this phase.

\section{Uranium in Layer Silicates}

Layer silicate minerals are known to have an affinity for uranyl species. They take up uranium by adsorption either onto the surface of the clay or within interlayer sites (AMES, 1983). The affinity for cation sorption depends on the clay mineralogy and the nature of the cation that compensates for the negative surface charge. At Fernald, bulk analysis of soil samples has suggested that uranium is associated with clay phases. In the present study, mica was found not to contain uranium, but a small amount of uranium 

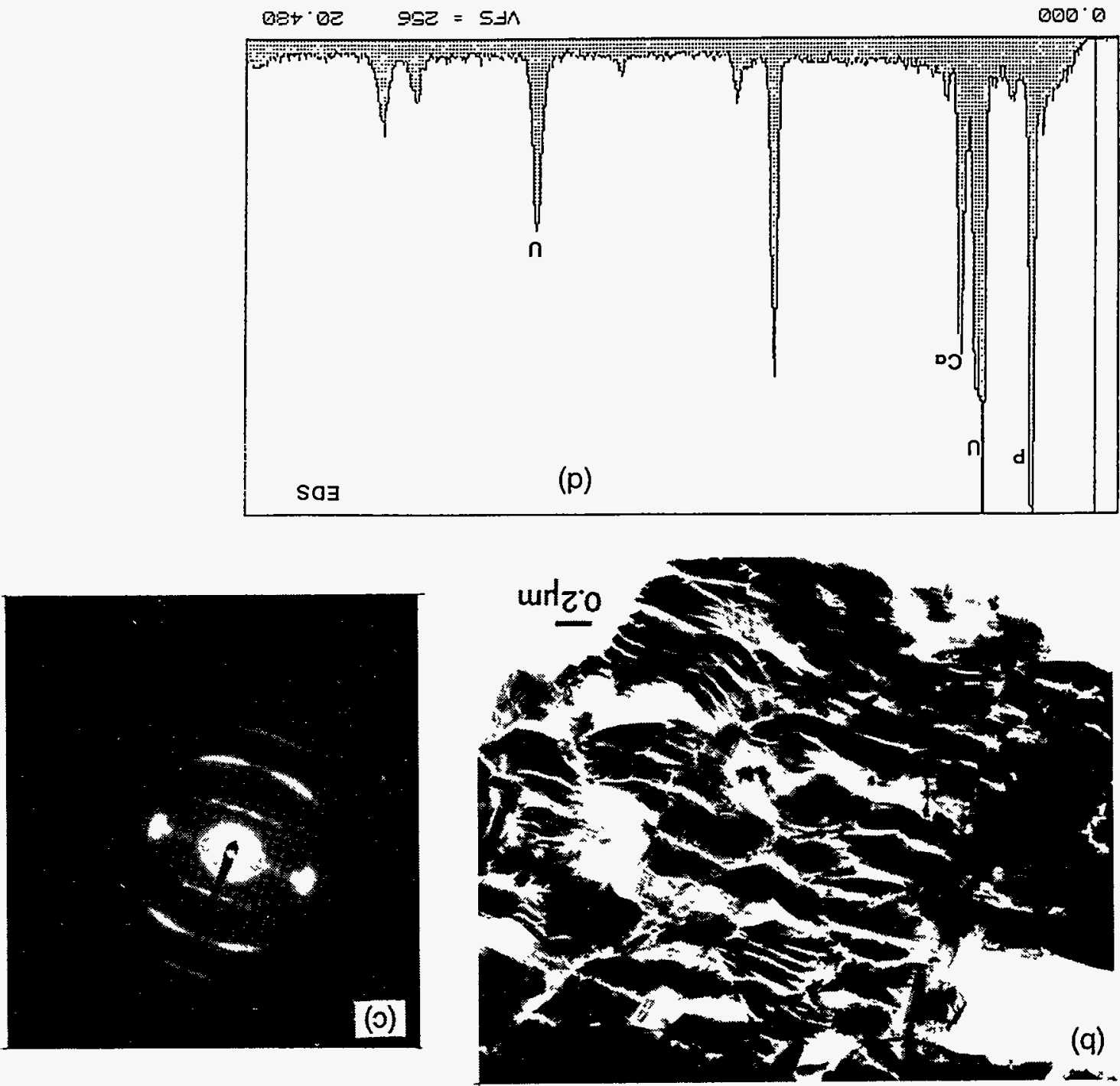

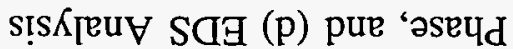

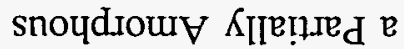

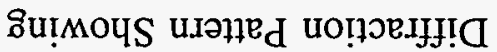

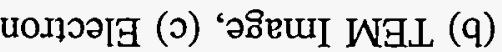

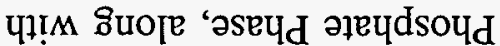

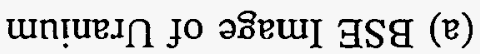

\section{- I I •}

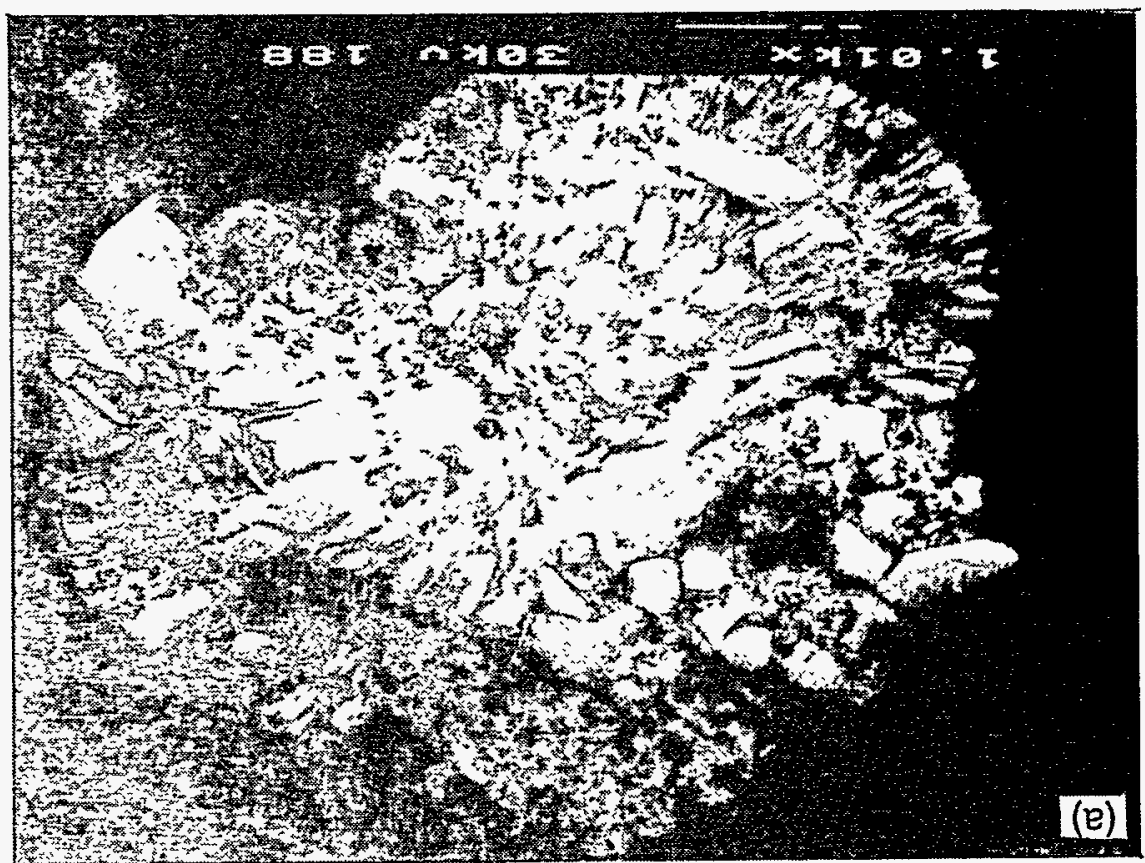



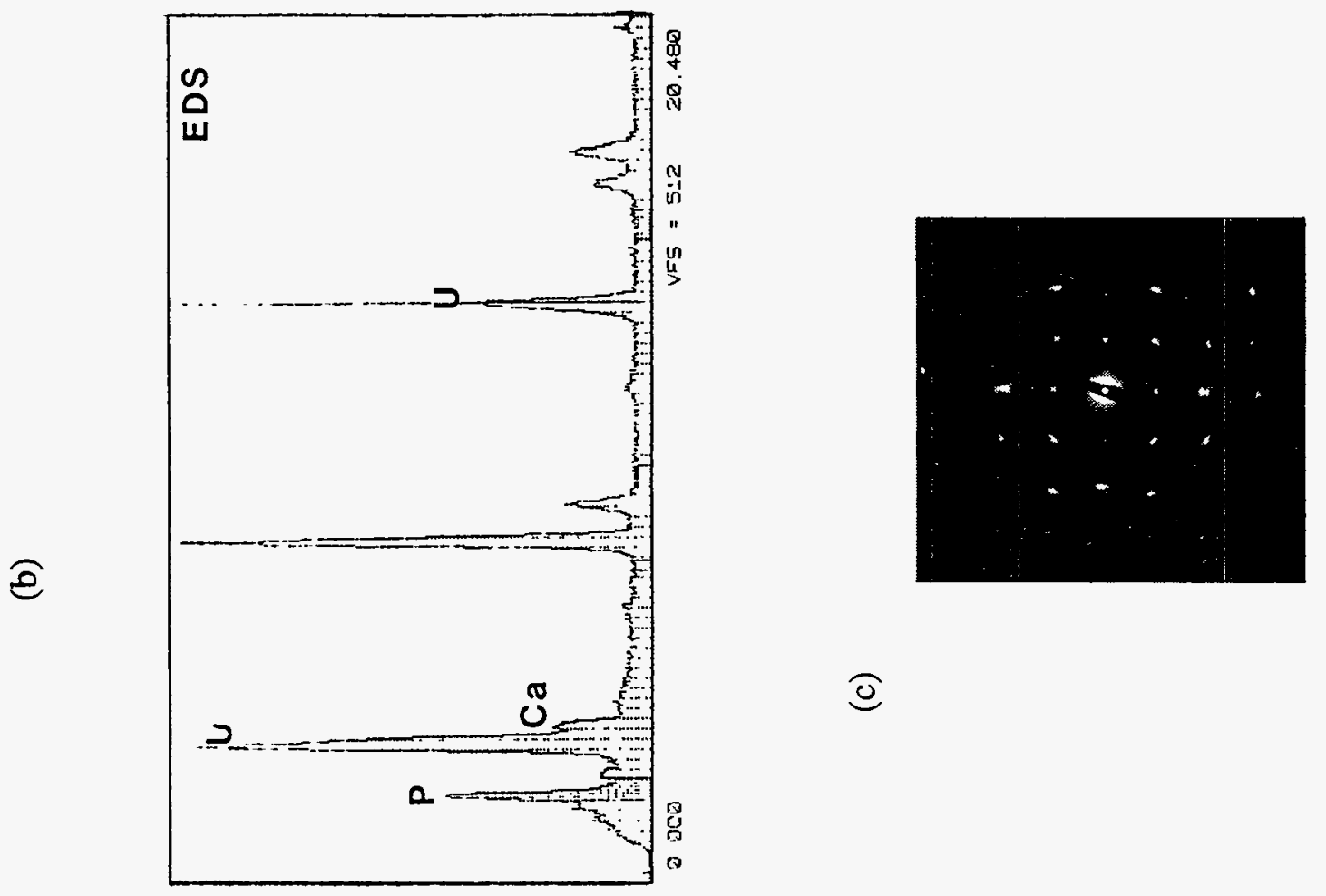

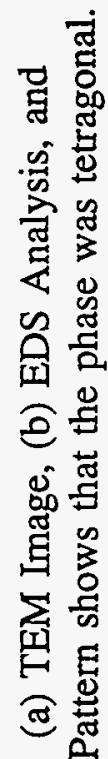

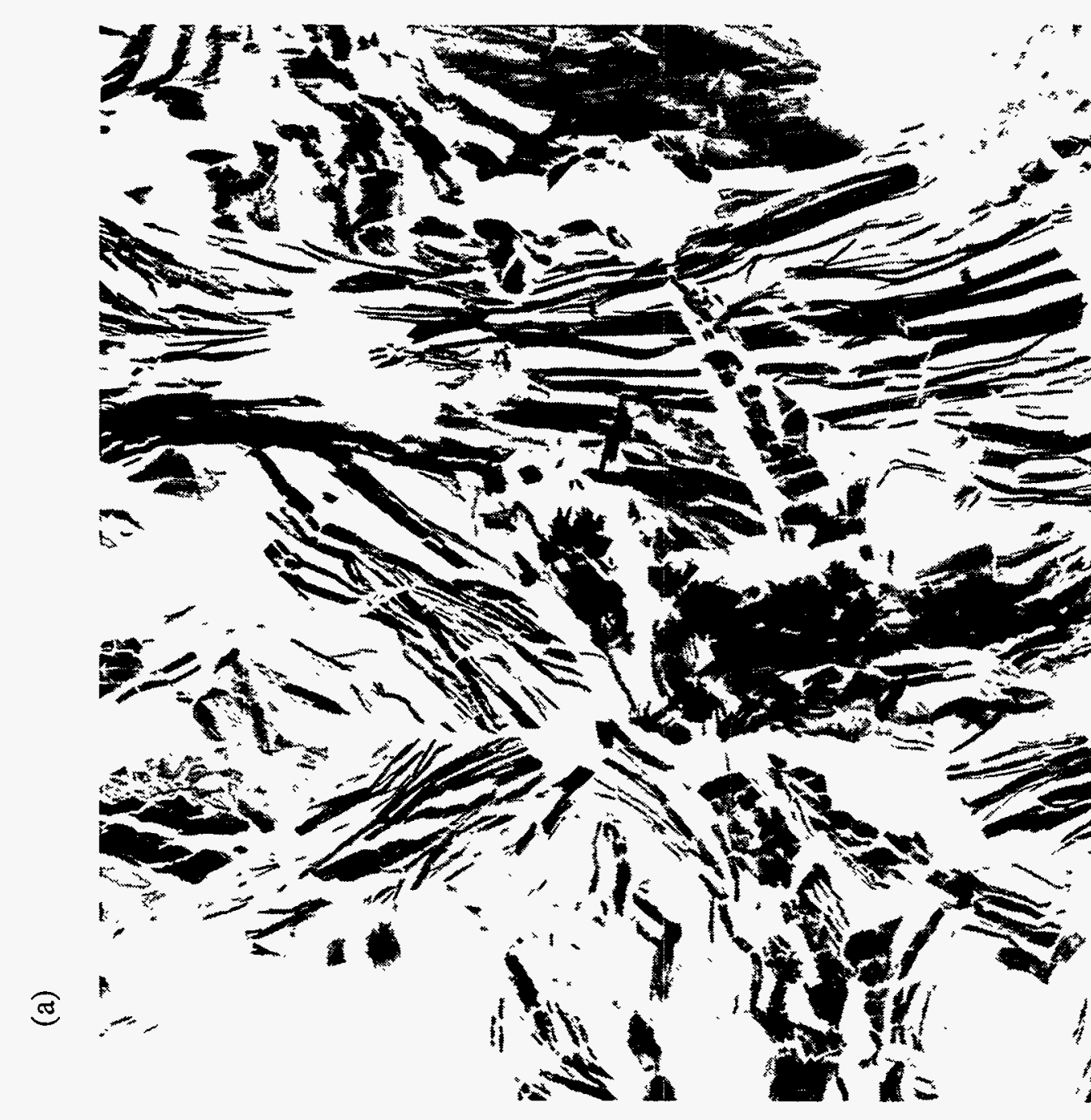

茫蓄 . 옹 岤 马े : $\therefore$ 类

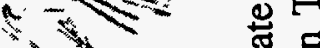
/ 窇 运 봉 灵 矛 곤 in 
(a)

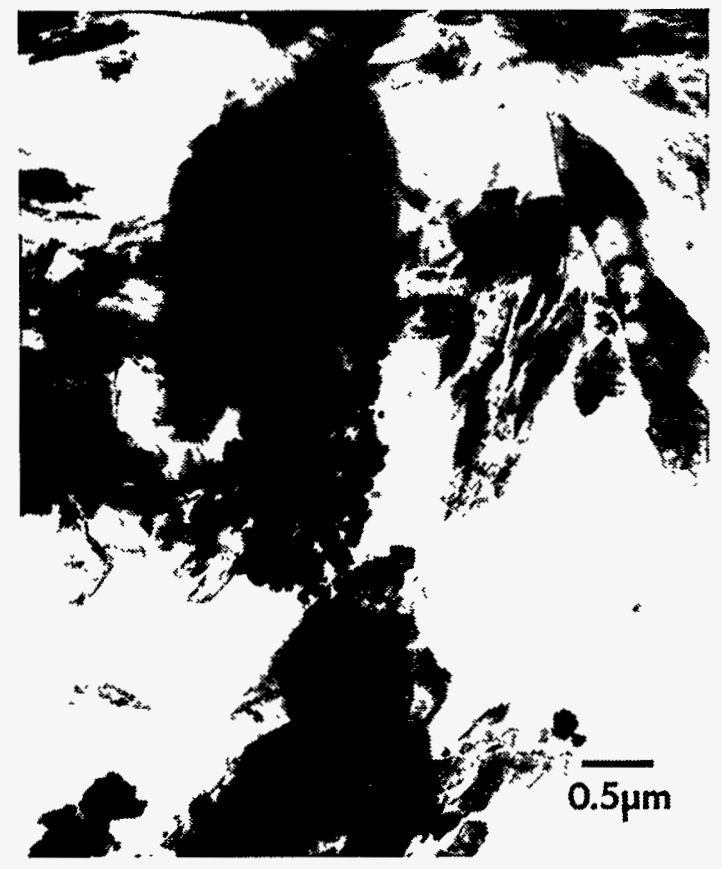

(b)

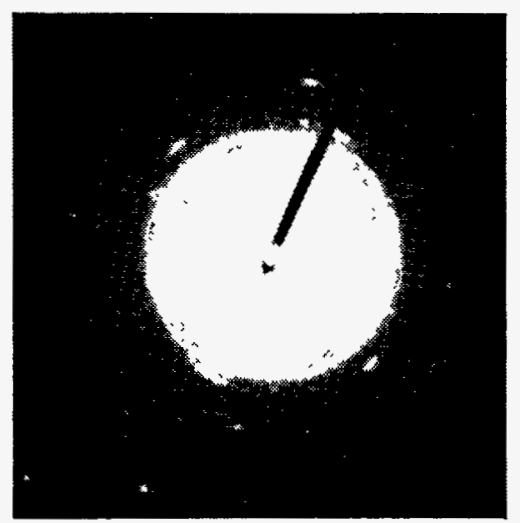

(c)

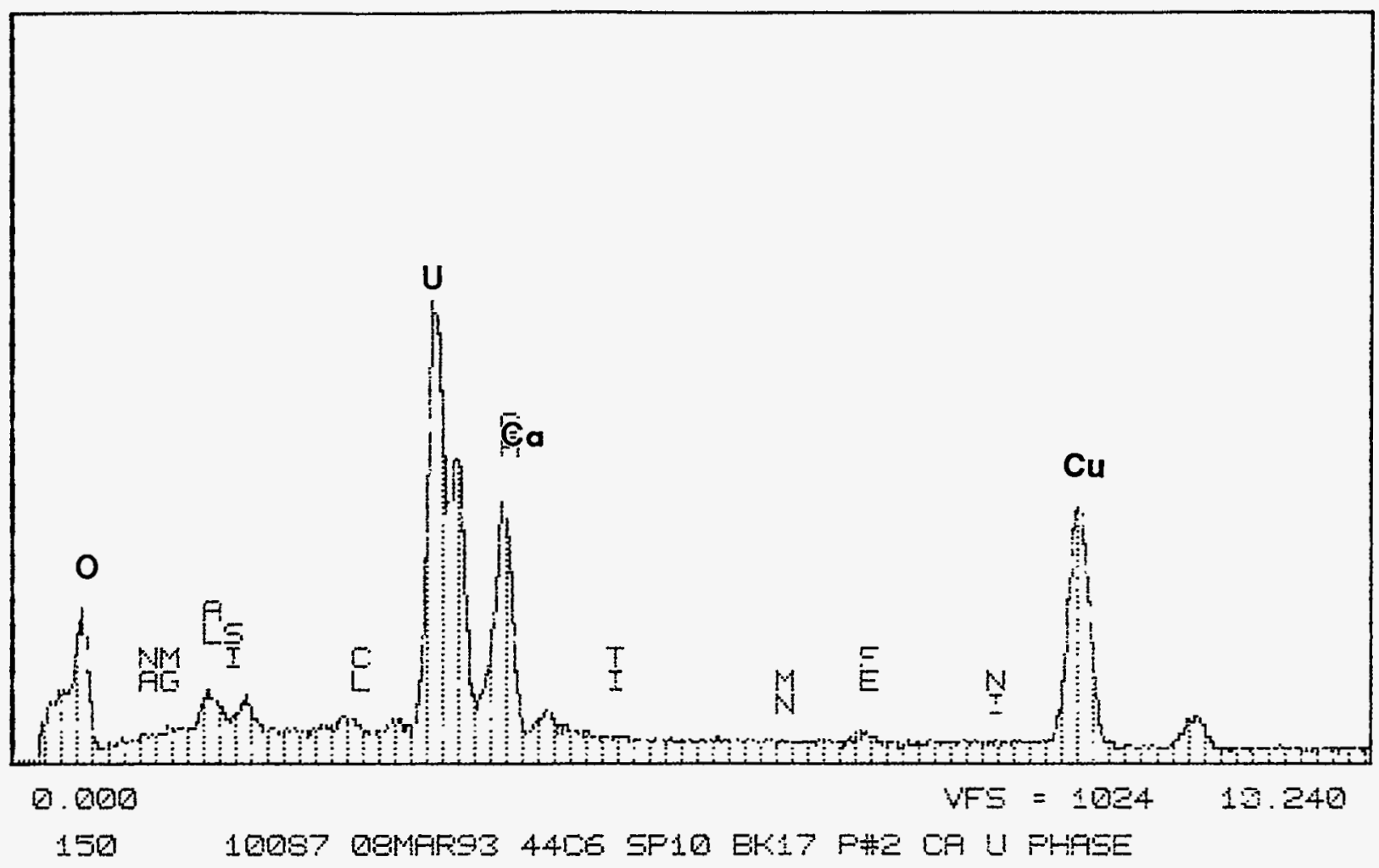

Fig. 13. (a) TEM Image of a Calcium Uranium Oxide Phase Found in SP2-3, with (b) SAED Pattern and (c) EDS Analysis 
Table 9. Electron Diffraction Data from Calcium Uranium Oxide Phase

\begin{tabular}{|c|c|c|}
\hline $\mathrm{d}$ spacings, $\AA$ & $\pm \AA^{\mathrm{a}}$ & Becquerelite (JCPDS 13-405), $\AA$ \\
\hline 7.28 & 0.18 & 7.44 \\
\hline 4.13 & 0.07 & \\
\hline 3.64 & 0.05 & $3.61,3.73$ \\
\hline 3.45 & 0.05 & $3.45,3.54$ \\
\hline 3.09 & 0.04 & 3.14 \\
\hline 2.51 & 0.04 & 2.53 \\
\hline 2.48 & 0.04 & 2.48 \\
\hline 2.06 & 0.03 & 2.06 \\
\hline 1.87 & 0.02 & 1.87 \\
\hline 1.38 & 0.01 & \\
\hline
\end{tabular}

${ }^{a}$ Errors are based on the inaccuracies associated with the measurement of the spacings and instrument instability.

( $<1$ wt \%) was thought to be associated, on occasion, with a chlorite-type clay. Chlorite alteration has been found to affect uranium redistribution at Koongarra, Australia (EDGHILL, 1991). At times, a high concentration of uranium in the clay phases was observed, but this material was later identified as a discrete uranium silicate phase (Fig. 14).

\section{Uranium Silicate Phase}

Crystalline uranium silicate phases were found in SP4, and the electron diffraction data from this phase (Table 10$)$ was consistent with soddyite $\left[\left(\mathrm{UO}_{2}\right)_{2}\left(\mathrm{SiO}_{4}\right) 2 \mathrm{H}_{2} \mathrm{O}\right]$, a uranyl silicate commonly found as an alteration product both in laboratory-reacted and fieldweathered uraninite (FINCH, 1992; WRONKIEWICZ, 1992). It has a high uranium-to-silicon ratio, which distinguishes it from other uranium silicates (STOHL, 1981). However, EDS analysis of the phase found in SP4 yielded a smaller than expected U:Si ratio, which was probably due to the difficulty in quantifying the uranium accurately. The presence of this phase does suggest that some weathering of the uranium has occurred in the core soil sample SP4 that was not observable with the optical microscope. The phase was found sandwiched between clay minerals (Fig. 14), which suggests that discrete uranium phases may be forming in the soil preferentially, rather than undergoing adsorption onto the clay minerals.

\section{Uranium Silicide Phase}

A large uranium-bearing phase identified by SEM was investigated with AEM. The particle was $>100 \mu \mathrm{m}$ long. Analysis by AEM showed that the phase did not contain significant quantities of oxygen. Quantitative analysis yielded the composition USi ${ }_{1.7}$. In addition, the phase was determined to be beam stable, which allowed a detailed phase determination. On the basis of the symmetry of three major zone axes, which were tilted during the analysis, the phase is probably cubic (Table 11 and Fig. 15). 


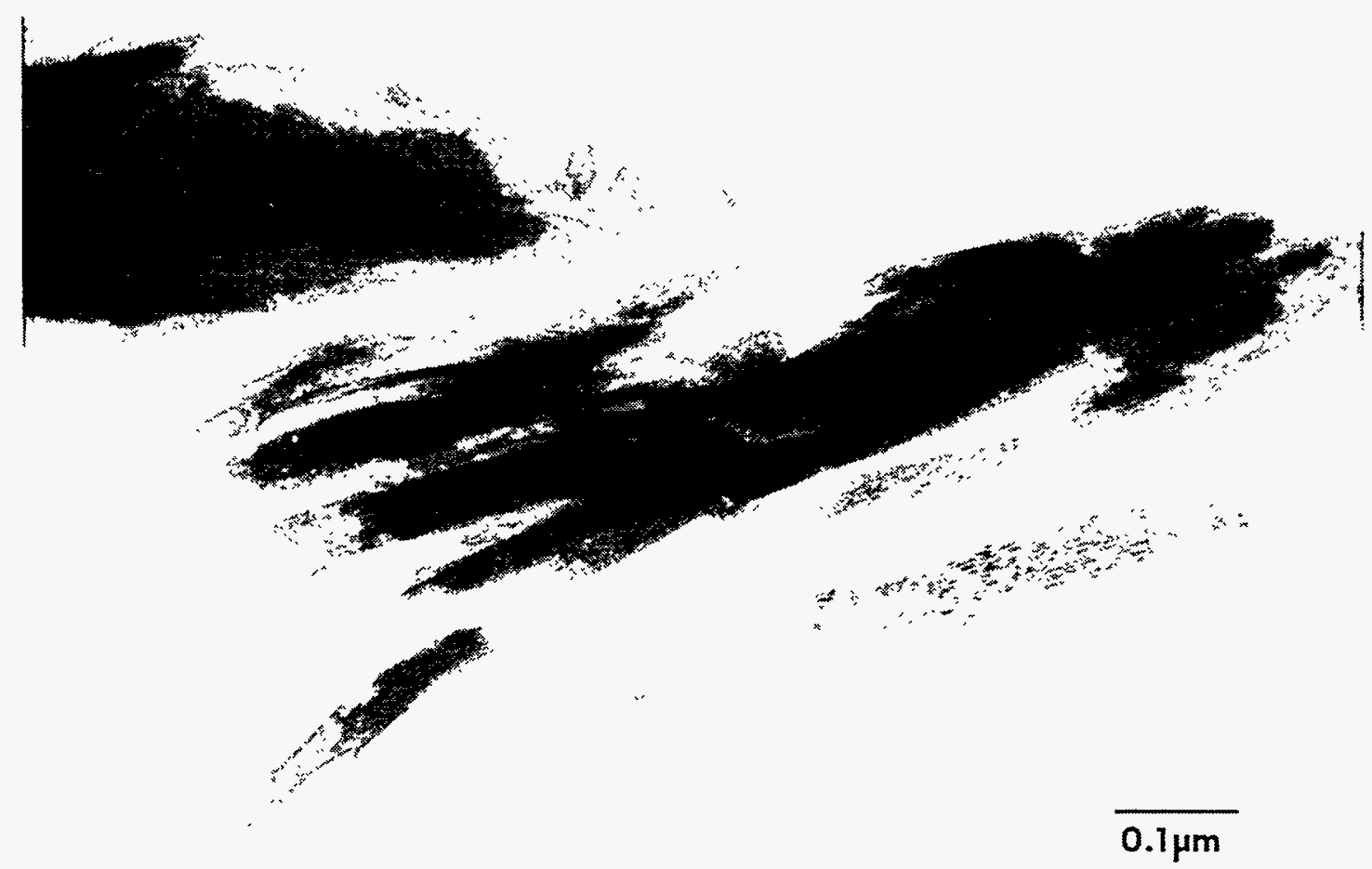

(a)

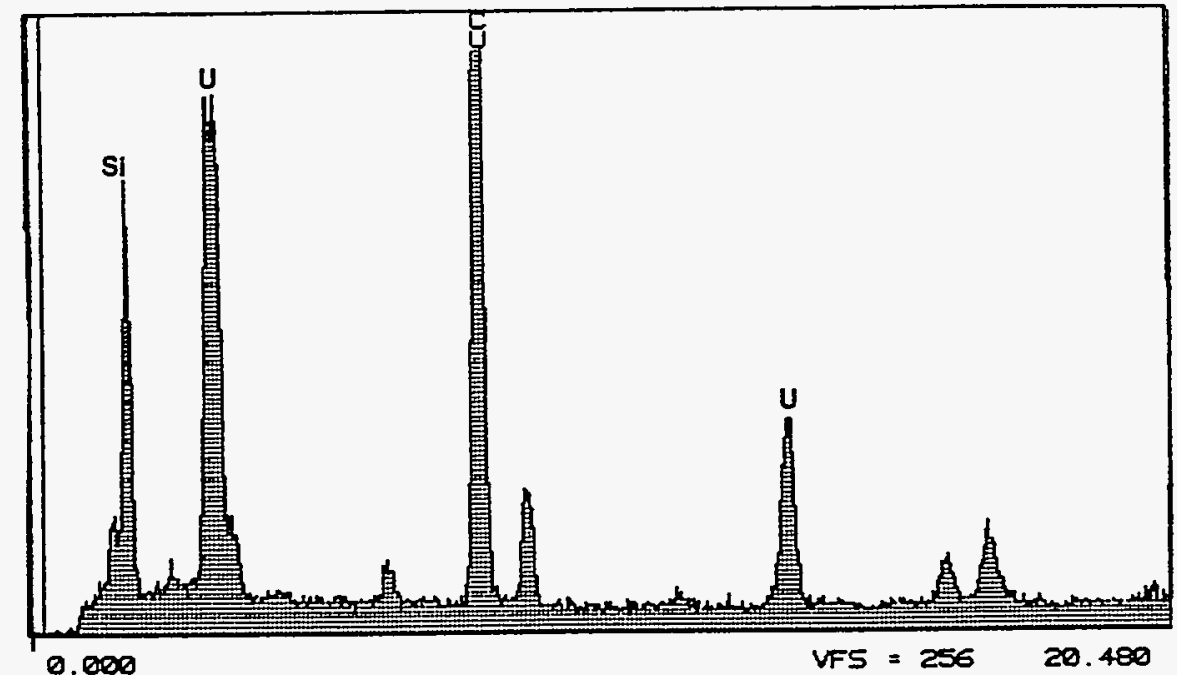

(b)

Fig. 14. (a) Micrograph of Uranium-Rich Silicate Phase Found in Clay and Identified as the Uranyl Silicate Soddyite $\left[\left(\mathrm{UO}_{2}\right)_{2} \mathrm{SiO}_{2} \cdot 2 \mathrm{H}_{2} \mathrm{O}\right]$ by Electron Diffraction (Table 10) and (b) EDS Compositional Analysis 


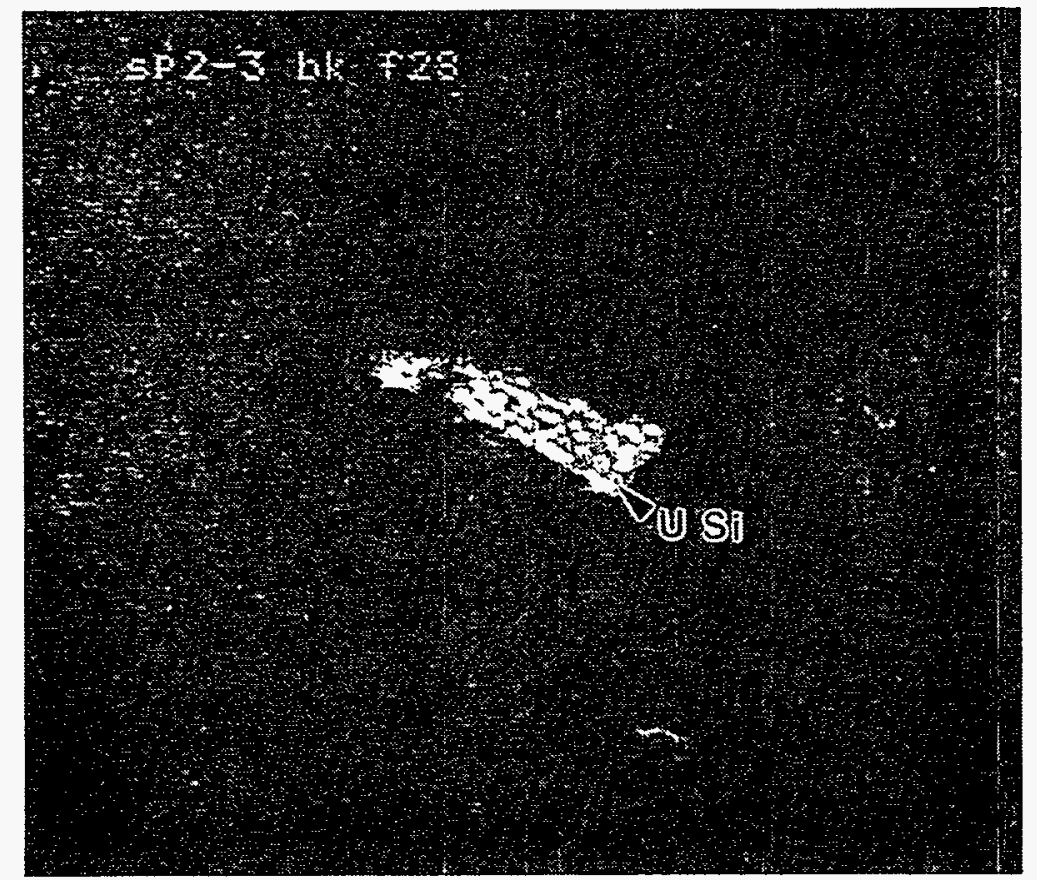

(a)

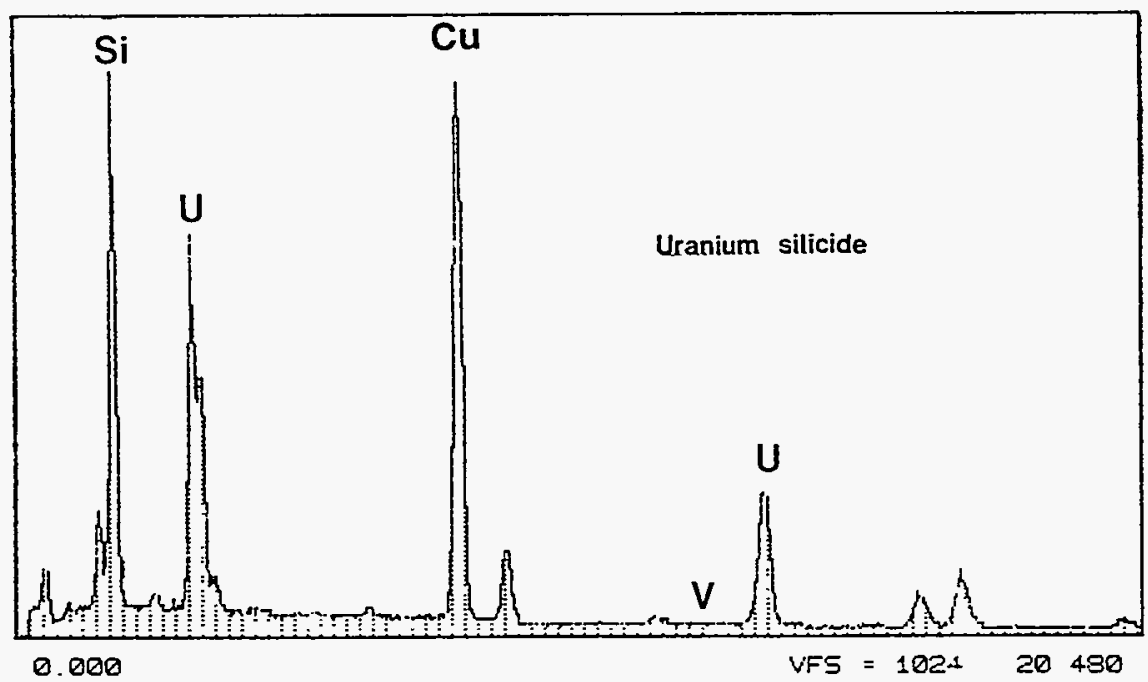

(b)

Fig. 15. (a) BSE Image of $>100-\mu \mathrm{m}$ Particle Containing Uranium and Silicon, Which Was Identified as a Uranium Silicide by (b) EDS, (c) TEM Image, and (d) a Series of Electron Diffraction Patterns 


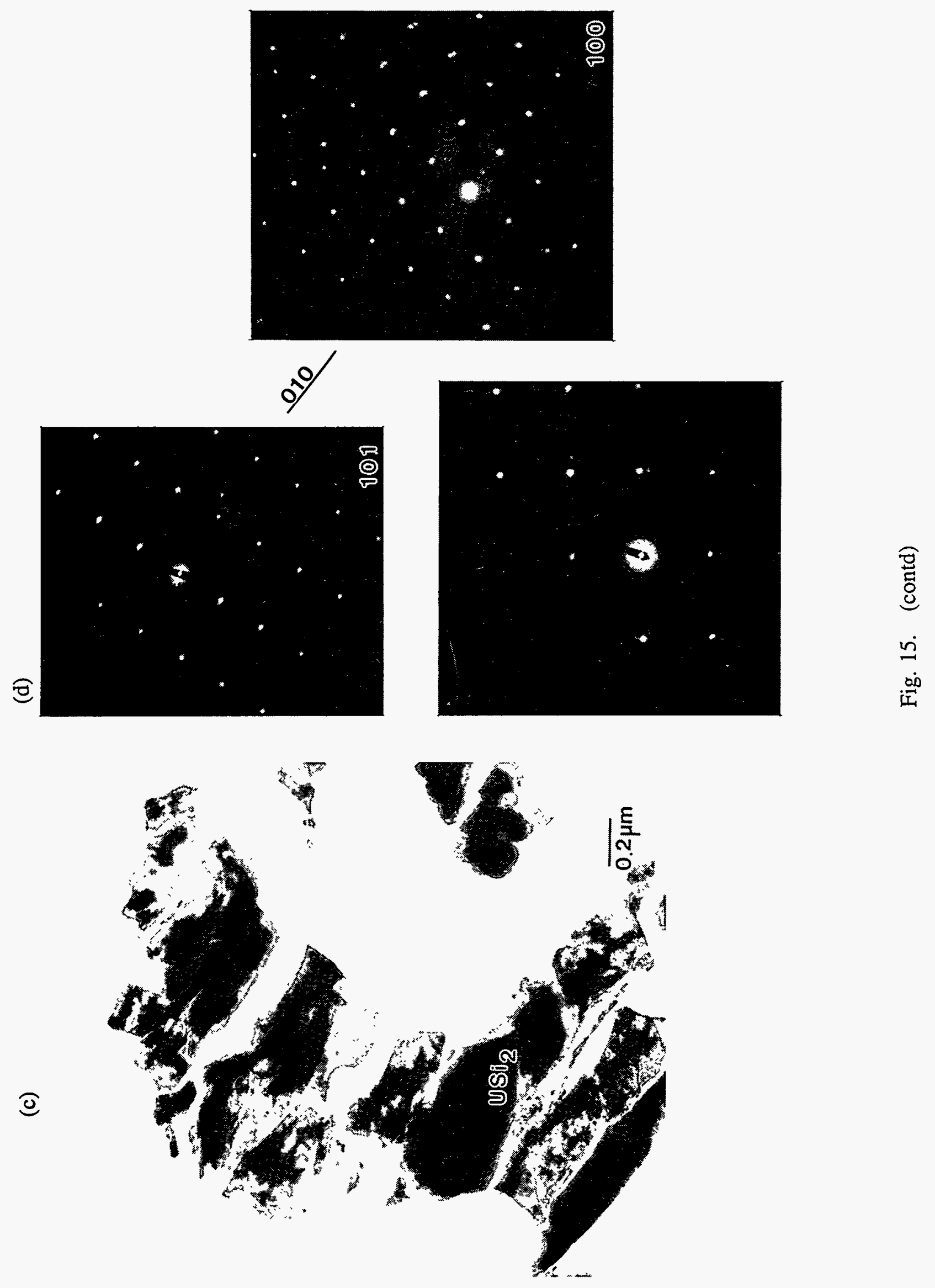


Table 10. Electron Diffraction Data from Uranium Silicate Phase

\begin{tabular}{|c|c|c|}
\hline $\mathrm{d}$ spacings, $\AA$ & $\pm \AA^{\mathrm{a}}$ & Soddyite (JCPDS 35-491), $\AA^{\mathrm{b}}$ \\
\hline 6.41 & 0.14 & 6.296 \\
\hline 4.89 & 0.09 & 4.805 \\
\hline 4.53 & 0.08 & 4.56 \\
\hline 3.79 & 0.06 & 3.803 \\
\hline 3.38 & 0.05 & 3.348 \\
\hline 2.75 & 0.04 & 2.720 \\
\hline 2.65 & 0.04 & 2.657 \\
\hline 2.52 & 0.04 & $2.52^{\mathrm{c}}$ \\
\hline 2.32 & 0.03 & 2.335 \\
\hline 1.88 & 0.03 & 1.864 \\
\hline 1.77 & 0.02 & 1.772 \\
\hline
\end{tabular}

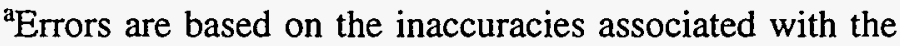
measurement of the spacings and instrument instability. [STOHL-1981].

${ }^{\mathrm{c}}$ Reflection observed in synthetic hydrated uranyl silicate [STOHL-1981].

Table 11. Electron Diffraction Data from Uranium Silicide

\begin{tabular}{|c|c|c|}
\hline $\mathrm{d}$ spacings, $\AA$ & $\pm \AA^{\mathrm{a}}$ & $\mathrm{USi}_{1.67}$ (JCPDS 13-0108), $\AA$ \\
\hline 4.13 & 0.07 & 4.08 \\
\hline 2.91 & 0.04 & 3.33 \\
\hline 2.36 & 0.03 & 2.57 \\
\hline 2.40 & 0.03 & \\
\hline 1.85 & 0.03 & 1.92 \\
\hline 1.68 & 0.02 & 1.66 \\
\hline
\end{tabular}

${ }^{a}$ Errors are based on the inaccuracies associated with the measurement of the spacings and instrument instability.

The composition of the phase matched closest with $\mathrm{USi}_{1.67}$, a hexagonal lattice with $\mathrm{a}=3.844 \AA$ and $\mathrm{c}=4.076 \AA$. However, electron diffraction data (see Table 11) did not match this phase. A series of nonstoichiometric uranium silicides exists with similar compositions and structures. Vaugoyeau et al. have determined the U-Si phase diagram [VAUGOYEAU, 1971]. The hexagonal USi ${ }_{1.67}$ can be formed at high temperature. The source of uranium silicide is unclear, though uranium silicides have been considered for use as nuclear fuels (HASTINGS, 1971). 


\section{Uranium Phosphite Phase}

The A14 soil samples contained uranium oxide, uranium phosphate (autunite), and particles of uranium phosphite $\left[\mathrm{U}\left(\mathrm{PO}_{3}\right)_{4}\right]$, a high-temperature phase. The uranium phosphite phase was not beam sensitive (a converged beam did not induce amorphization), suggesting that this phase is probably not an alteration product but was formed in the incinerator (Table 12).

Table 12. Electron Diffraction Data from Uranium Phosphite

\begin{tabular}{|c|c|}
\hline $\mathrm{d}$ spacings, $\AA$ & $\begin{array}{c}\mathrm{U}\left(\mathrm{PO}_{3}\right)_{4} \\
\text { (JCPDS 20-1348), } \AA\end{array}$ \\
\hline 6.64 & 6.27 \\
\hline 5.13 & 5.13 \\
\hline 4.40 & 4.41 \\
\hline 3.825 & 3.85 \\
\hline 3.65 & 3.66 \\
\hline 2.715 & 2.70 \\
\hline 3.17 & 3.14 \\
\hline 2.96 & 2.95 \\
\hline 2.21 & 2.20 \\
\hline 1.80 & \\
\hline 2.15 & 2.16 \\
\hline 2.02 & 2.02 \\
\hline
\end{tabular}

${ }^{a}$ Errors are based on the inaccuracies associated with the measurement of the spacings and instrument instability.

Uranium(IV) metaphosphate $\left[\mathrm{U}\left(\mathrm{PO}_{3}\right)_{4}\right]$ can be formed by reaction of $\mathrm{U}_{3} \mathrm{O}_{8}$ or $\mathrm{UO}_{2}$ with an excess of $\mathrm{P}_{2} \mathrm{O}_{5}$ in the temperature range $400^{\circ}$ to $1100^{\circ} \mathrm{C}$, or by reaction of UP, $\mathrm{UO}_{2}$, or $\mathrm{U}_{3} \mathrm{O}_{8}$ and concentrated phosphoric acid followed by crystallization (induced by heating to $400^{\circ} \mathrm{C}$ ). Treatment of $\mathrm{U}_{3} \mathrm{O}_{8}$ with ammonium hydrogen phosphate at $1000^{\circ} \mathrm{C}$ followed by heating with phosphoric acid at $600^{\circ} \mathrm{C}$ will also yield $\left[\mathrm{U}\left(\mathrm{PO}_{3}\right)_{4}\right]$. The phase has been structurally characterized by Douglass (DOUGLASS, 1962). There are several references on the structure of $\left[\mathrm{U}\left(\mathrm{PO}_{3}\right)_{4}\right]$, although its unit cell dimensions have not been established (Table 13).

\section{Oxidation State Determination by Electron Energy Loss Spectroscopy}

Some effort was devoted to determining whether EELS could be used to determine the oxidation state of uranium in uranium-bearing phases. The $\mathrm{N}_{4,5}$ edges of uranium occur at $738 \mathrm{eV}$ and $780 \mathrm{eV}$. These edges are weak but their energies could be calibrated more 
Table 13. Crystallographic Data for $\alpha$ - and $\beta-\left[U\left(\mathrm{PO}_{3}\right)_{4}\right]$ (modified from GMELIN, 1981)

\begin{tabular}{|l|l|c|c|c|c|c|c|}
\hline Phase & Symmetry & a, $\AA$ & b, $\AA$ & c, $\AA$ & $\alpha$ & $\beta$ & $\gamma$ \\
\hline$\beta-\left[\mathrm{U}\left(\mathrm{PO}_{3}\right)_{4}\right]$ & Orthorhombic & 8.95 & 14.95 & 6.89 & & & \\
\hline$\alpha-\left[\mathrm{U}\left(\mathrm{PO}_{3}\right)_{4}\right]$ & Orthorhombic & 6.913 & 14.967 & 8.986 & & & \\
\hline$\beta-\left[\mathrm{U}\left(\mathrm{PO}_{3}\right)_{4}\right]$ & Orthorhombic & 13.80 & 14.92 & 9.00 & & & \\
\hline$\alpha-\left[\mathrm{U}\left(\mathrm{PO}_{3}\right)_{4}\right]$ & Monoclinic & 23.42 & 13.02 & 23.00 & & 90.0 & \\
\hline$\alpha-\left[\mathrm{U}\left(\mathrm{PO}_{3}\right)_{4}\right]$ & Triclinic & 15.43 & 8.147 & 8.734 & 117.64 & 112.59 & 89.08 \\
\hline$\alpha-\left[\mathrm{U}\left(\mathrm{PO}_{3}\right)_{4}\right]$ & Triclinic & 15.43 & 8.147 & 15.47 & 89.80 & 115.15 & 89.08 \\
\hline
\end{tabular}

accurately than those of the $M_{4,5}$ edges, as the oxygen $K$-edge and carbon edges from the support film were present within $500 \mathrm{eV}$. In this region, a less intense beam was required, so that radiation-induced changes were reduced. The high electron beam intensities and long integration times required to observe the uranium $M$ edges resulted in the complete amorphization of the uranium-bearing phase of interest. The object of examining these edges was to look for a shift in energy of the edge, which was analogous to the technique used to determine oxidation state with XAS. The shift between oxidation states for the $\mathrm{N}$ edges was expected to be around $2 \mathrm{eV}$, which is as great as the error in the energy determination. However, the energy resolution of the microscope/ energy loss spectrometer, operating at $200 \mathrm{kV}$, was only about $1.5 \mathrm{eV}$. The shift in the energy of the edge was not noticeable. Therefore, the efforts to use EELS to determine oxidation states were discontinued. Instead, the structural identifications were used to deduce oxidation state. This approach has been shown to be effective for a majority of uranium-bearing phases.

\section{E. Estimation of Uranium Distribution and Concentration}

In addition to using the SEM to locate uranium-bearing particles, the principles of stereology were used to obtain information on the distribution of uranium-bearing phases, as well as an estimate of the uranium concentration in the sample.

The distribution of uranium-bearing phases was calculated by estimating the volume of each particle found and comparing its volume to the total volume. Knowledge of the uranium content in each phase was required to determine the total uranium contribution of a certain phase. For instance, in the carbonate-treated A14 soil samples provided by C. Francis (ORNL), 15 uranium-bearing particles were located. Analysis by SEM/EDS tentatively separated the uranium-rich particles into three groups: uranium-calcium-phosphorus phases, uranium-only phases (possibly uranium oxide), and uranium-magnesium phases. The uranium-calcium-phosphorus phases accounted for around $70 \%$ of the uranium in the sample, while the uranium-only phases accounted for about $25 \%$ and the uranium-magnesium phases for the remaining 5\%. Analytical electron microscopy will be used to make positive 
identification of the phases, which will be necessary to confirm the percentage of each uranium-bearing phase in the soil.

The uranium concentration can be estimated by using the total soil surface area examined and the area and uranium content of uranium-rich particles. For the carbonatetreated A14 soil, stereology showed the uranium concentration to be about $2000 \mathrm{ppm}$, which was above the original bulk uranium concentration of the A14 soil ( $\sim 500 \mathrm{ppm})$. The overestimate in uranium content may also have resulted from incorrect uranium phase assignment because the phases have not, as yet, been identified by AEM; thus, the true density of the uranium-bearing phases was not accounted for.

\section{F. Soil Remediation Support}

This section describes some of the efforts to support soil remediation with electron beam methods of characterization (BUCK, 1994a). We have examined soil samples from (1) a separation based on density differences, (2) a citrate and carbonate extraction process, and (3) a dithionite/Tiron extraction procedure.

\section{Density Separation of A14 Soil}

A gravimetrically separated sample of A14 soil was found to contain two major phases, uranium oxide and uranyl phosphate. The TEM micrographs suggested that the phosphate was the weathering product of the uranium oxide. Figure 16 shows the fibrous particles of the uranium phosphate phase. The uranium phosphate phase appeared to be connected to the uranium oxide, suggesting that the uranium phosphate was an alteration product. The SAED pattern produced was square and had spacings of $5.02 \AA$ and $6.88 \AA$. Other patterns were obtained, for which the spacings of the (001) plane were calculated to be $\sim 9$ to $10 \AA$. The phase was identified on the basis of these patterns as a tetragonal metaautunite uranyl phosphate hydrate $\left[\mathrm{M}^{2+}\left(\mathrm{UO}_{2}\right)_{2}\left(\mathrm{PO}_{4}\right)_{2} \bullet \mathrm{H}_{2} \mathrm{O}\right]$.

Figure 16 shows the effect of the uranium phase separation based on density differences (CHAIKO, 1993) for A14 soil. Most of the contamination was in the form of large particles, and these phases were identified by means of AEM as uranium oxide and uranium phosphate (indicated in the figure). Bulk uranium chemical analysis showed that this experiment (CHAIKO, 1993) did not isolate all the uranium, which may suggest that such physical separation processes can only be used successfully with a few phases.

Aqueous biphasic separation (ABS) is currently being evaluated for removing uranium from Fernald soils. The ABS process should be able to separate $\mathrm{UO}_{2}$ from clay. Samples from the biphasic extraction procedure will soon be examined. In these studies supporting soil remediation efforts, it has been important to determine the path taken by some of the silicate phases, such as quartz and clay, in the treatment process. 


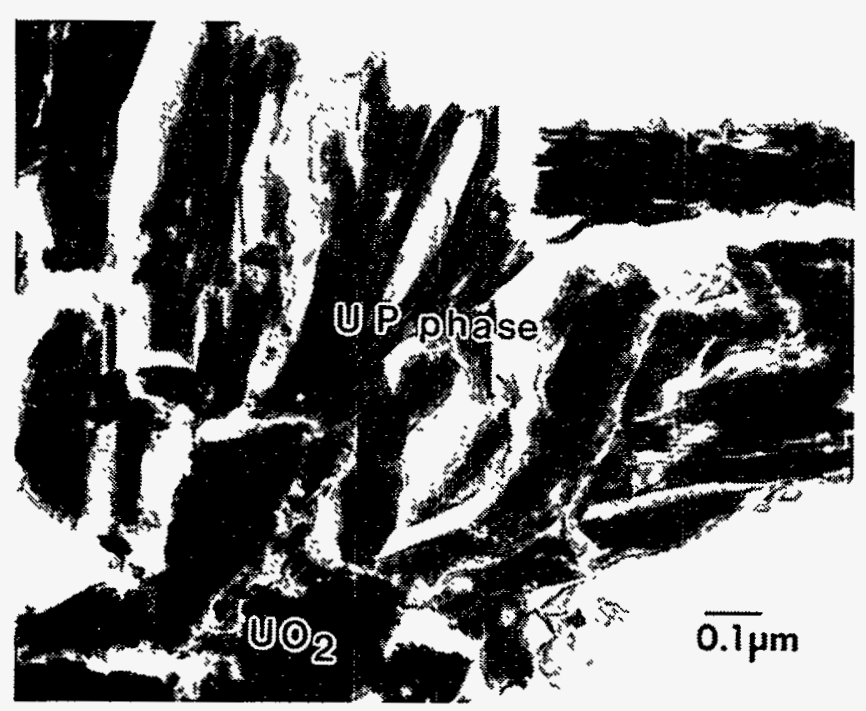

Fig. 16. TEM Image of the Density-Separated A14

Soil Sample Showing Evidence of Weathering.

The darker clumps were identified as uranium oxide, and attached to them were uranium phosphate crystallites.

\section{Citrate/Carbonate Extraction of A14 Soil}

Electron beam examination of A14 soil samples that had undergone the carbonate/citrate extraction procedure showed that the soil contained a number of heavy metals other than uranium. Cerium phosphate, yttrium phosphate, and some thorium-bearing phases were also observed in both treated and untreated soils. In addition, the treated soils contained many zircon particles. Morphologically and compositionally, there was little difference between the treated and untreated soils, suggesting that the soil was not damaged.

Uranium phosphates $\left[\mathrm{U}\left(\mathrm{PO}_{3}\right)_{4}\right]$ and uranium oxide $\left[\mathrm{UO}_{2+\mathrm{x}}\right]$ particles were observed in soil samples AX15T20 and AY15T20 (citrate- and carbonate-treated A14 soil samples). The phases were usually $<10 \mu \mathrm{m}$ in diameter. In addition to the tetravalent uranium oxide phase $\left[\mathrm{UO}_{2}\right]$ found in these samples, a uranium metaphosphate $\left[\mathrm{U}\left(\mathrm{PO}_{3}\right)_{4}\right]$ was also observed. This phase was the electron-beam-stable uranium phosphite. (Figure 17 shows the AEM characterization of the uranium-bearing phase and the SEM/BSE image.) Most uranium phosphate phases, particularly the uranyl phosphates (autunites), have tended to become amorphous after even short beam exposures. The uranium [U(IV)] species observed in these citrate- and carbonate-treated soils have been found to be resistant to radiation damage, which allows more accurate data to be obtained from them. This finding suggests that the species do not contain hydrated water, as the presence of water in the crystal structure often adds to the beam instability of the phase. Electron diffraction patterns from this phase have been examined, and the patterns reflect a highly symmetric crystal lattice. 

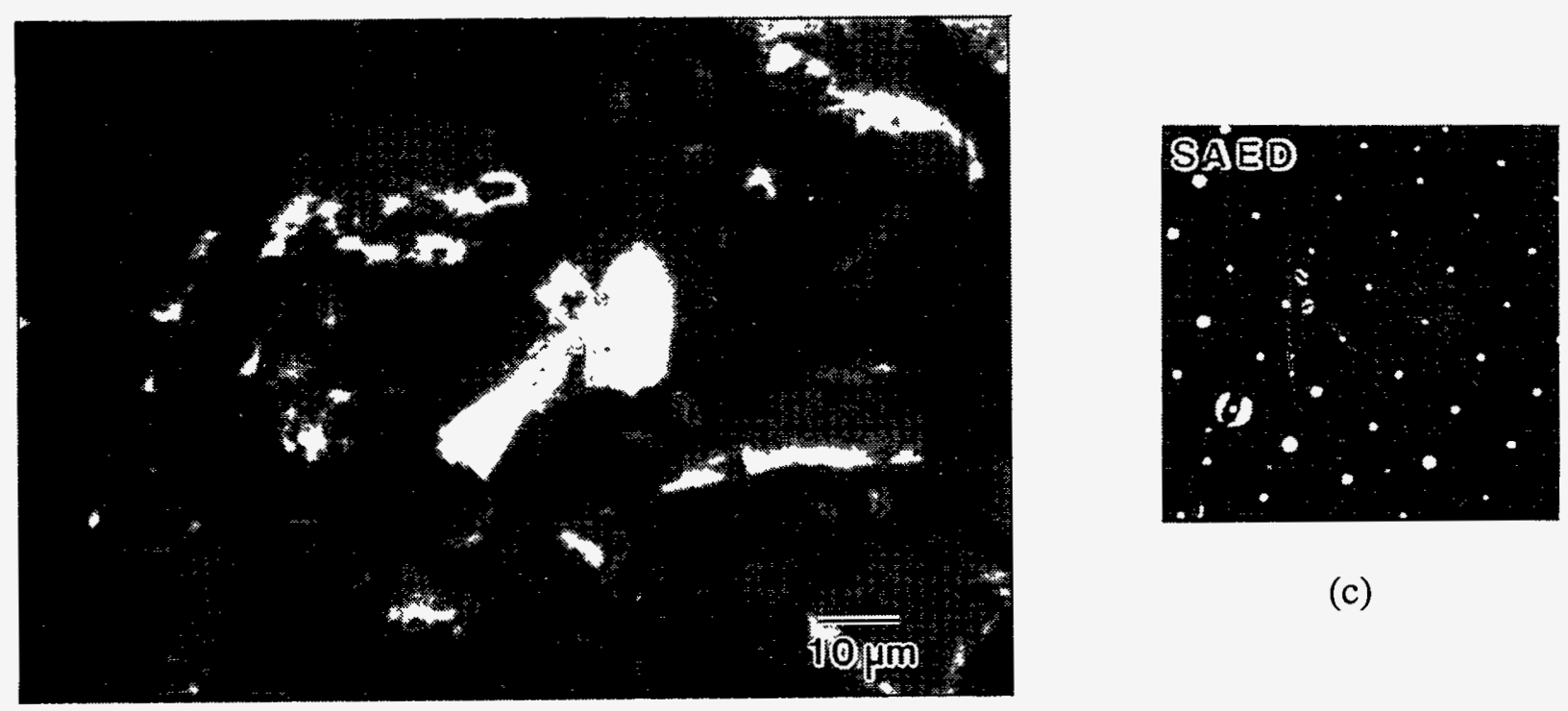

(c)

(a)
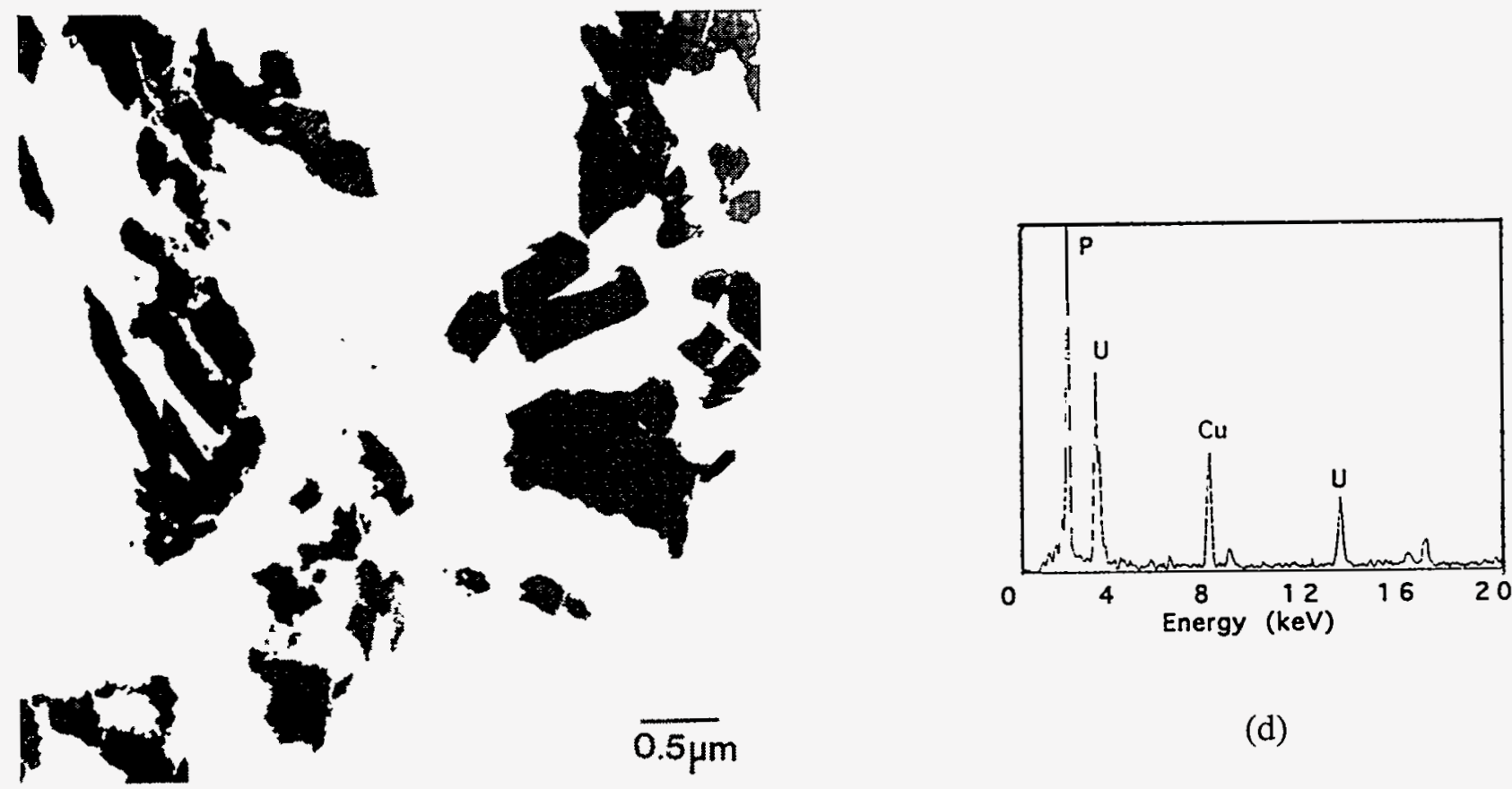

(b)

Fig. 17. Example of the Ceramic-Like Uranium Phosphite Phase in Soil Sample A14 (citrate treated): (a) BSE Image of Phase, Where Bright Contrast Is Related to Atomic Number; (b) TEM Image; (c) SAED Pattern; and (d) EDS Analysis. The phase is regularly shaped and does not possess the fine needles, which have been observed in the autunite phases. 
No difference has been observed between the two size fractions $(<20 \mu \mathrm{m}$ and $20-75 \mu \mathrm{m}$ fractions). The differences between the two complexing agents were also difficult to find, as similar phases occurred in both samples.

The citrate and carbonate complexing agents are effective at removing [U(VI)] species, but are less effective with [U(IV)] species. From the AEM study, it is apparent that particulate uranium [U(IV)] phases are still present in the soil after treatment. With AEM, uranium-bearing phases have been located and identified. These results have helped the soil washing group at ORNL understand why this process isn't completely removing the uranium and should help the group to improve their cleanup technology.

Electron beam analysis of carbonate- and citrate-treated A14 soil samples continues to find the uranium [U(IV)] phosphite $\left[\mathrm{U}\left(\mathrm{PO}_{3}\right)_{4}\right]$. The phase is regularly shaped and does not possess the fine needles that have been observed in the autunite phases. This phase is unlikely to be a weathering product but is probably a high-temperature phase that originated in the incinerator.

The citrate- and carbonate-treated A14 soil samples that we examined had around 180-250 ppm uranium, whereas untreated A14 soil samples had around $500 \mathrm{ppm}$ uranium. The majority of the uranium (60-75\%) observed in the treated soils was in the form of uranium phosphites $\left[\mathrm{U}\left(\mathrm{PO}_{3}\right)_{4}\right]$; about $20 \%$ was uranium oxide $\left[\mathrm{UO}_{2}\right]$; and the remainder was uranyl phosphate. It is apparent that the remediation procedure is not removing this type of contamination.

\section{Dithionite/Tiron Extraction of A14 Soil}

Experiments conducted at LANL have concentrated on the use of Tiron (1,2dihydroxy-3,5-benzenedisulfonic acid) for the dissolution of uranium under reducing conditions. In this technique of soil remediation, the [U(VI)] species are reduced with dithionite, and the [U(IV)] species are complexed with Tiron. This technology was selected on the basis of XAS investigations, which indicated that $\sim 80 \%$ of the uranium in Fernald soils was [U(VI)]. Oxygen donor ligands, such as phosphate, bind strongly to [U(VI)]. The AEM analysis of A14 soil samples treated by the LANL dithionite/Tiron procedure has shown that this method of treatment is not selectively removing particular species.

Uranium phosphorus phases (autunite), uranium oxide, and uranium phosphites were observed in untreated, dithionite-treated, and dithionite/Tiron treated samples (all identifications are tentative until confirmed by TEM analysis). A uranium iron phase observed in the untreated soils was absent from the treated samples.

Untreated A14 soil samples contained uranium oxide particles, as identified by TEM. Evidence for uranium weathering at Fernald was found in these samples. A large calcium uranium phosphate phase was found by SEM (Fig. 18).

The nonuranium-bearing particles have also been analyzed in an effort to understand how the added chemicals alter the soil phases. Quartz, layer silicates, calcium 


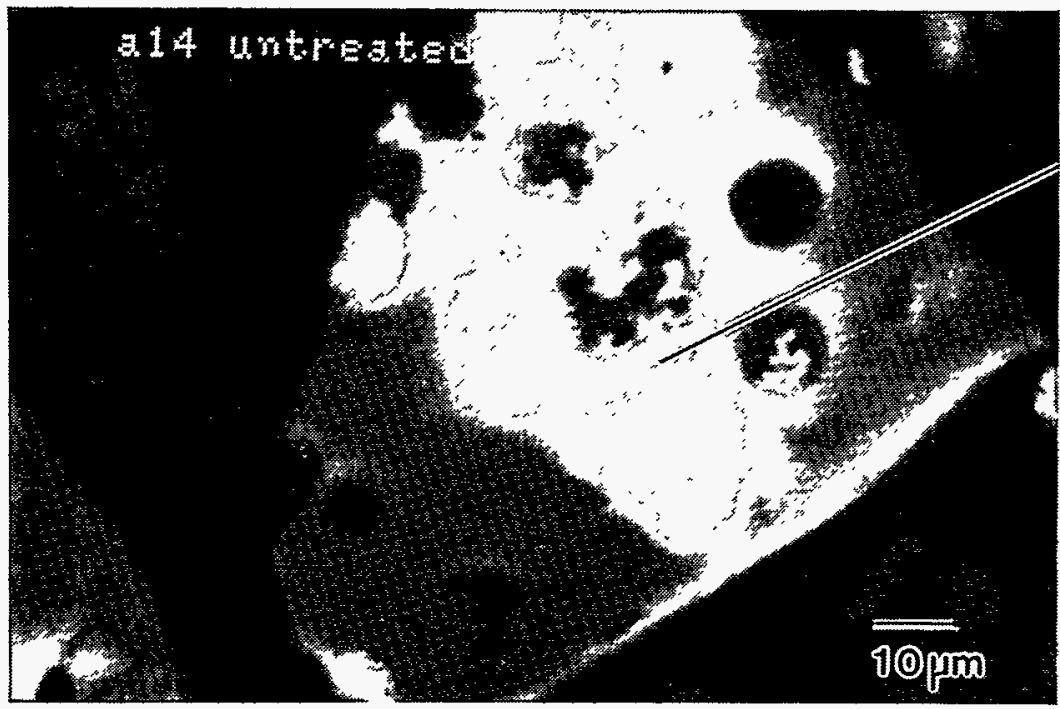

Fig. 18. BSE Image Showing Uranium Oxide Surrounded by Calcium Phosphate Phase in Sample A14. Oxide is undergoing alteration into uranyl phosphates.

phosphate, cerium phosphate, and zircon were present in the A14 soil samples. Work is continuing to determine whether any of these phases was altered by the remediation technology.

On the basis of the SEM analyses of untreated and treated A14 soil samples, the distribution of uranium-bearing phases in the samples has been determined (Table 14).

Table 14. Distribution of Uranium Phases (\%) in Dithionite/Tiron-Treated Soil Samples

\begin{tabular}{|l|c|c|c|}
\hline Phase & A14 (ANL) & A14 (LANL) & $\begin{array}{c}\text { Dithionite/ } \\
\text { Tiron }\end{array}$ \\
\hline Meta-autunite & 80 & 55 & 68 \\
\hline $\begin{array}{l}\text { Uranium Meta- } \\
\text { phosphate }\end{array}$ & 10 & 34 & 27 \\
\hline Uranite & 8 & 5 & 3 \\
\hline $\begin{array}{l}\text { Other Uranium } \\
\text { Phases }\end{array}$ & 2 & 5 & 2 \\
\hline
\end{tabular}


The table shows estimated weight percentages of uranium associated with specific phases in the untreated A14 soil samples supplied by D. Chaiko of ANL and J. Brainard of LANL. The results confirm the observation by Morris et al. (1992) that $\sim 80 \%$ of the uranium in the untreated A14 soil supplied by ANL was in the U(VI) state; however, the untreated A14 soil supplied by LANL only contained $\sim 55 \%$ of uranium in the U(VI) state. The SEM and TEM are unable to readily identify uranium which is not in a particulate form; hence, any adsorbed uranium will not be accounted for in these estimates. Uranium-bearing particles from the untreated soils were, on average, larger than those from treated samples. The uranium phosphates, as well as the cerium phosphate phases, were still present in the treated soils. The distribution of the major uranium-bearing phases in the treated soils suggests that the extraction technique is not working on the particulate contamination. The ceramic-like uranium phosphites are not being completely broken down and removed, and much of the uranium phosphate still remains.

The dithionite/Tiron process does not appear to be working in exactly the manner expected. Uranyl phases continue to be observed in the treated soils in spite of the presence of the reducing agent. The observation that the particles in the treated samples were smaller suggests that surface reaction is occurring, and perhaps repeated extraction may yield improved results.

\section{G. Redistribution of Uranium in Fernald Soils}

Electron beam analysis of uranium particles in Fernald soils has revealed evidence of substantial redistribution of uranium. Uranium oxides have been observed surrounded by weathering products such as uranium phosphates (BUCK, 1994b). In Fig. 18 the micrograph shows a uranium oxide particle which is surrounded by weathered phases. The surrounding matrix is a calcium phosphate phase. The uranyl phosphates constitute a very diverse group of uranium-bearing minerals. The most common type, autunite, is characterized by a U:P ratio of 1:1. Phosphuranylites are another group of uranyl phosphates, which have a U:P ratio of $3: 2$. They are often closely associated with uraninite in natural systems. Uranyl phosphates will control the uranium concentration in groundwaters, as they have solubilities below those of uranyl silicates.

Finch and Ewing (FINCH, 1992) have indicated that the formation of autunite requires the presence of a lead-containing uranyl hydrate, curite, which acts as a catalyst for the formation of uranyl phosphate, at least in groundwaters with a low phosphate concentration. However, uranyl phosphates will precipitate if a high phosphate concentration $\left(\sim 10^{-2} \underline{\mathrm{M}}\right)$ exists. Therefore, the question is whether such a high $\left[\mathrm{PO}_{4}{ }^{3-}\right]$ concentration exists in Fernald soils. Apatite controls the $\left[\mathrm{PO}_{4}{ }^{3-}\right]$ concentration in many natural waters and will keep phosphorus levels below $10^{-7} \mathrm{M}$ when the $\mathrm{pH}$ exceeds 7 . In the Fernald soils, we have observed the presence of calcium phosphate (hydroxyapatite) and iron phosphate, which are sources for phosphorus in the soil. Much of the phosphate may have come from fertilizers used in farming and from the weathering of rocks. According to Lee and Marsh (LEE, 1992), the soil $\mathrm{pH}$ was around 8 for all soil samples, suggesting that $\left[\mathrm{PO}_{4}{ }^{3-}\right]$ concentrations will not be high. In other words, because uranium phosphates are so insoluble, phosphates in solution were continually removed as the uranium-bearing phases were formed. 
The formation of insoluble phosphate phases may prevent uranium from entering the food chain. For example, soluble lead salts, emitted from car exhausts, often form phosphates in soils, which plants cannot assimilate (NRIAGU, 1981). If these uranium phosphate phases are found to be insoluble enough in terms of risk assessment, then they could be left in the soil. 


\section{CONCLUSIONS AND RECOMMENDATIONS}

\section{A. Implications for Remediation Technologies}

The application of optical microscopy, SEM, and AEM provided a clearer picture of uranium contamination at Fernald. The evidence suggests that some of the weathering processes at Fernald have resulted in the alteration of the initial uranium-bearing phases, and that soluble uranium interacted only slightly with the clay phases in the soil substrate.

Removal of uranium from the Fernald soils can be enhanced by detailed knowledge of the chemical and physical characteristics of the contamination and its environment. The characterization methods described above, in combination with other methods under development (LEE, 1992; CUNNANE, 1993; MORRIS, 1992; BERTSCH, 1993), will allow remediation technology groups to find more direct and efficient ways of removing the contamination. Characterization of contaminated sites following the EPA protocol (EPA, 1992) will allow the most efficient remediation technology to be developed. These techniques can be transferred for implementation at contaminated sites operated by the DOE and the private sector. Electron-beam techniques for the characterization of soil samples have already been used with uranium- and thorium-contaminated soils from a site belonging to Ecotek, Inc. (BROWN, 1994), and are also being used for studying plutonium contamination at Johnston Atoll (BRAMLITT, 1988; WOLF, 1994). At Johnston Atoll, a conveyor belt technique developed by Thermo-Analytical is being used to isolate contaminated soil and allow volume reduction. This technique requires detailed soil analysis to determine whether the technique is feasible or whether another technique should be adopted. Evidence suggests that because plutonium has redistributed within calcite particles, the technique will be unable to effectively reduce the volume of contaminated soils. At Hanford (SHEPPARD, 1979), Rocky Flats (RYAN, 1993), and Maxey Flats (CLEVELAND, 1981), similar techniques for soil site characterization could be applied.

Without information describing the nature of the uranium contamination (i.e., phase identification, oxidation state determination, and distribution of the uranium-bearing phase), remediation technologies will operate by trial and error, which may result in repetitive processing and an even greater volume of contamination than was initially present. The combination of novel characterization techniques, such as AEM, XAS, luminescence, and SEM, allows remediation techniques to be developed and tailored depending on the nature of uranium in the soil.

\section{B. Summary}

The soil samples SP4, SP2-3, and SP5 contained many uranium-containing phases. Sample SP4 was the only one that did not contain the phosphate phases. Most of the phases were uranium in a very fine form (uranium oxide particles $\sim 20 \mathrm{~nm}$ in diameter) and uranium adsorbed onto iron oxides. Soil SP4 has been found to be one of the easiest soil samples to clean. However, samples from the incinerator site (A14) and other regions of the plant (such as SP2-3) have been found to be difficult to clean, even with repeated extraction procedures. This situation may reflect the particulate nature of the uranium in these soil samples. On the 
basis of AEM data, treatment with carbonate/citrate and dithionite/Tiron will not remove some of the intractable uranium phases, suggesting that perhaps a different approach is required. Further studies of soil and processed samples will continue to investigate the effectiveness of separation processes by characterizing the uranium-bearing phases isolated from the soil.

Selected samples from SP4, SP2-3, SP5, A14, and B16 have been examined by optical microscopy, combined with SEM and AEM. With these methods of analysis, we were able to isolate and characterize discrete uranium-bearing phases in the Fernald soils. With optical microscopy, no large uranium-bearing secondary minerals were observed. With SEM, however, uranium-rich regions were identified. Upon further examination with AEM, these regions were found to be composites of finely dispersed phases, which were both crystalline and amorphous. Little uranium was associated with the clay substrate itself. The types of uranium-bearing phases observed at Fernald, such as amorphous uranium iron oxides phases, uranium calcium phosphates, and oxidized uraninite, are similar in many cases to those found in other environments. While it is necessary to show that these results apply to larger soil samples (this has been done, to some extent, by comparing results with XAS), the utility of using multiple electron beam and optical microscopy techniques for uranium phase identification and characterization has been demonstrated.

\section{Future Work}

Further detailed analysis has been planned for FY 1994. Analysis of the effect of carbonate and citrate complexants on the uranium in the B16 soils will continue. Continued AEM examination of samples SP9 and SP4 from J. Brainard (LANL), who is developing the biochelator extraction procedure, will be undertaken. These tests focus on the use of a synthetic analogue of microbially produced complexing agents (known as Tiron). The catalyst (dithionite) has been used to reduce the uranyl ion to U(IV), to assist complexing with Tiron. Samples from the biphasic extraction procedure of D. Chaiko (ANL) will also be examined (CHAIKO, 1993). Bioremediation technologies are an alternative method to remove contaminants from soil. At the Idaho National Engineering Laboratory, A. E. Torma et al. (TORMA, 1994) are conducting a process in which $\mathrm{Fe}^{3+}$ is used to oxidize U(IV) to U(VI), then bacteria are used to oxidize the reduced iron. The uranium is removed by a highly acidic solution $(\mathrm{pH}=2)$. Treated samples from this program will be examined. 


\section{ACKNOWLEDGMENTS}

This work was supported by the U.S. Department of Energy, Office of Technology Development, as part of the Uranium in Soils Integrated Demonstration Program, under Contract W-31-109-ENG-38. Isolation of uranium in sample A14 by density differences was achieved by D. Chaiko of Argonne National Laboratory (ANL). Washing of soil sample A14 by carbonate and citrate complexing agents was performed by $\mathrm{C}$. Francis of Oak Ridge National Laboratory (ORNL), and the extraction of uranium by the dithionite/Tiron procedure was performed by J. Brainard of Los Alamos National Laboratory (LANL). Site soil samples were provided by S. Y. Lee of ORNL and D. E. Morris of LANL. Optical investigations were aided by R. C. Ewing of the University of New Mexico. 


\section{REFERENCES}

AMES, 1983

L. L. Ames, J. E. McGarrah, and B. A. Walker, "Sorption of Uranium and Radium by Biotite, Muscovite, and Phlogopite," Clays and Clay Minerals 31, 343 (1993).

BERTSCH, 1993

P. M. Bertsch, D. B. Hunter, S. R. Sutton, S. Bajt, and M. L. Rivers, In Situ Speciation of Uranium in Soils and Sediments by Micro X-ray Absorption Spectroscopy, Progress Report, Fernald Environmental Management Project, Ohio (1993).

BLANK, 1968

H. Blank and C. Ronchi, "Electron Diffraction of $\mathrm{U}_{4} \mathrm{O}_{9}$," Acta Cryst. A24, 657 (1968).

BLANK, 1969

H. Blank and C. Ronchi, "Versetzungen in Kubischen Uranoxiden," J. Nucl. Mater. 31, 1-12 (1969).

BRAMLITT, 1988

E. T. Bramlitt, "Plutonium Mining for Clean-up at Johnston Atoll," Health Physics 55, 451 (1988).

BROWN, 1994

N. R. Brown, B. Carlson, E. C. Buck, N. L. Dietz, and J. K. Bates, "Characterization of U and Th Contaminated Soils from a Nuclear Fuel Facility," presented at Waste Managment '94, Tucson, AZ (1994).

BUCK, 1993a

E. C. Buck, J. K. Bates, N. L. Dietz, and J. C. Cunnane, "AEM Examination of Uranium Contaminated Soils from the DOE Fernald Operation Site," Proc. of the Waste Management '93 Conf., 19th Annual Nuclear Waste Symp., Tucson, AZ, February 28-March 4, 1993, Vol. 1, 797-801 (1993).

BUCK, 1993b

E. C. Buck, N. L. Dietz, N. R. Brown, J. K. Bates, and J. C. Cunnane, "Uranium Contaminated Soils: Ultramicrotomy and Electron Beam Analysis," submitted to Journal of Electron Microscopy Technique (1993).

BUCK, 1994a

E. C. Buck, N. R. Brown, N. L. Dietz, and J. C. Cunnane, "Supporting Soil Remediation by Electron Beam Methods," Proc. of the Waste Management '94 Conf., 20th Annual Nuclear Waste Symp., Tucson, AZ, 2131-2135 (1994). 
BUCK, 1994b

E. C. Buck, N. R. Brown, and N. L. Dietz, "The Distribution of Uranium-Bearing Phases in Fernald Soils," Mater. Res. Soc. Symp. Proc. 333, 437-444 (1994).

CHAIKO, 1993

D. J. Chaiko, R. Mesah-Biney, and E. Van Deventer (Argonne National Laboratory), "Soil Decontamination by Aqueous Biphasic Extraction," Part 4 in Removal of Uranium from Uranium Contaminated Soils. Phase I: Bench-Scale Testing, Oak Ridge National Laboratory Report ORNL-6762 (September 1993).

CHISHOLM, 1992

C. J. Chisholm-Brause, S. D. Conradson, P. G. Eller, and D. E. Morris, "Changes in U(VI) Speciation upon Sorption onto Montmorillonite from Aqueous and Organic Solutions," Mater. Res. Soc. Symp. Proc. 257, 315-322 (1992).

CLEVELAND, 1981

J. M. Cleveland and T. F. Rees, "Characterization of Pu at Maxey Flats," Science 212, 1506 (1981).

CLIFF, 1975

G. Cliff and G. W. Lorimer, "The Quantitative Analysis of Thin Sections," J. Microscopy 103, 203 (1975).

CUNNANE, 1993

J. C. Cunnane, S. Y. Lee, D. L. Perry, V. C. Tidwell, J. Schwing, K. R. Nuhfer, and G. Weigand, "Field Demonstration of Technologies for Characterization of Uranium Contamination in Surface and Subsurface Soils," Proc. of the Waste Management '93 Conf., 19th Annual Nuclear Waste Symp., Tucson, AZ, February 28-March 4, 1993, Vol. 1, pp. 803-809 (1993).

DOUGLASS, 1962

R. M. Douglass, "Crystallographic Data for Orthorhombic Uranium (IV) Metaphosphate and Plutonium (IV) Metaphosphate," Acta. Cryst., 15, 505-506 (1962).

EDGHILL, 1991

R. Edghill, "The Redistribution of Uranium with Weathering in the Koongarra Uranium Deposit," Radiochimica Acta 52/53, 381-386 (1991).

EPA, 1992

U.S. EPA, Characterization Protocol for Radioactive Contaminated Soils, U.S. Environmental Protection Agency, Office of Solid Waste and Emergency Response, Washington, DC, Publication 9380.1-10FS, May 1992. 
FINCH, 1992

R. J. Finch and R. C. Ewing, "Alteration of Natural $\mathrm{UO}_{2}$ under Oxidizing Conditions from Shinkolobwe, Katanga, Zaire: A Natural Analogue for the Corrosion of Spent Fuel," Radiochimica Acta 53/54, 391 (1992).

GHABRU, 1990

S. K. Ghabru, A. R. Mermut, and R. J. St. Arnaud, Soil. Sci. Soc. Am. J. 54, 281 (1990).

GMELIN, 1981

GMELIN Handbook of Inorganic Chemistry, Supplement Vol. C14, "Uranium Compounds with P, As, Sb, Bi, and Ge," Springer-Verlag, Berlin (1981).

GMELIN, 1986

GMELIN Handbook of Inorganic Chemistry, Uranium Supplement Vol. C5, "Optical and Spectroscopic Properties," Springer-Verlag, Berlin (1986).

HASTINGS, 1971

I. J. Hastings, "Burnup and Temperature Dependence of Swelling in $\mathrm{U}_{3} \mathrm{Si}, "$ J. Nucl. Mater. 41, 195-202 (1971).

HAYAT, 1989

M. A. Hayat, Principles and Techniques of Electron Microscopy: Biological Applications,

3rd ed., CRC Press Inc., Boca Raton, FL (1989).

HSI, 1985

C-K. Hsi and D. Langmuir, "Adsorption of Uranyl onto Ferric Oxyhydroxides: Application of the Surface Complexation Site-Binding Model," Geochimica et Cosmochimica Acta 49, 1931 (1985).

JANECZEK, 1991

J. Janecsek and R. C. Ewing, "X-Ray Powder Diffraction Study of Annealed Uraninite,"

J. Nucl. Mater. 185, 66- 77 (1991).

JOHNSON, 1988

L. H. Johnson and D. W. Shoesmith, "Spent Fuel," in Radioactive Wasteforms for the

Future, Eds., W. Lutze and R. C. Ewing, Elsevier, Netherlands, p. 665 (1988).

KAY, 1965

D. Kay, Techniques for Electron Microscopy, Blackwell Press, Oxford, 1965.

KRASEVEC, (1983)

V. Krasevec, A. Prodan, J. Holc, and D. Kolar, "Transmission Electron Microscopy Study of Reduced $\mathrm{Ca}_{2} \mathrm{UO}_{5}$," J. Sol. Stat. Chem. 48, 300-305 (1983). 
LEE, 1992

S. Y. Lee and J. D. Marsh, Characterization of Uranium Contaminated Soils from DOE Fernald Environmental Management Project Site: Results of Phase I Characterization, ORNL/TM-11980, Oak Ridge National Laboratory, 1992.

MORRIS, 1992

D. E. Morris, S. D. Conradson, C. Drew-Tait, C. J. Chisholm-Brause, J. Berg, and J. Musgrave, Uranium Speciation in Fernald Soils, Los Alamos National Laboratory Progress Report, May (1992).

NEIHESEL, 1992

J. Neihesel, Petrographic Methods in Characterization of Radioactive and Mixed Waste, Hazardous Materials Control Resources Institute, Superfund'92, Monitoring and Sampling, pp. 192-195 (1992).

NRIAGU, 1981

J. O. Nriagu, "Formation and Stability of Base Metal Phosphates in Soils and Sediments," in Phosphate Minerals, Chapter 10, p. 327.

RYAN, 1993

R. Ryan, (U.S. Department of Energy, Rocky Flats Plant), Personal Communication, Fernald Progress Meeting, San Antonio, TX, October 1993.

SANDINO, 1992

A. Sandino and J. Bruno, "The Solubility of $\left[\left(\mathrm{UO}_{2}\right)_{3}\left(\mathrm{PO}_{4}\right)_{2} \cdot 4 \mathrm{H}_{2} \mathrm{O}\right]_{(\mathrm{s})}$ and the Formation of [U(VI)] Phosphate Complexes: Their Influence in Uranium Speciation in Natural Waters," Geochimica et Cosmochimica Acta 56, $4135-4145$ (1992).

SATO, 1965

R. Sato, "Layer Faults in Oxygen Deficient $\mathrm{U}_{3} \mathrm{O}_{8}$," Int. Conf. Elec. Diff. Cryst. Defect, Melbourne, Australia, IIC-3 (1965).

SHEPPARD, 1979

J. C. Sheppard, M. J. Campbell, J. A. Kittrick, and T. L. Hardt, "Retention of Np, Am, and Cm by Diffusible Soil Particles, Environ. Sci. Technol. 13, 680 (1979).

STOHL, 1981

F. V. Stohl and D. K. Smith, "The Crystal Structure of Uranyl Silicate Minerals," American Mineralogist 66, 610 (1981).

TORMA, 1993

A. E. Torma, J. E. Wey, R. Reddy, and J. C. Cunnane, "Uranium Extraction from Contaminated Soils by Bioprocessing," presented at Waste Managment '94, Tucson, AZ (1994). 
VAUGOYEAU, 1971

H. Vaugoyeau, L. Lombard, and J. P. Morlevat, "Contribution à l'étude du diagramme d'équilbre uranium-silicium," J. Nucl. Mater. 39, 323-329 (1971).

VEBLEN, 1990

D. R. Veblen, G. D. Guthrie, K. J. T. Livi, and R. C. Reynolds, "Illite/Smectite Transformation," Clays and Clay Minerals 38, 1 (1990).

WILLIS, 1978

B. T. M. Willis, "The Defect Structure of Hyper-Stoichiometric Uranium Dioxide," Acta Cryst. A34, 88-90 (1978).

WRONKIEWICZ, 1992

D. J. Wronkiewicz, J. K. Bates, T. J. Gerding, E. Veleckis, and B. S. Tani, "Uranium Release and Secondary Phase Formation during Unsaturated Testing of $\mathrm{UO}_{2}$ at $90^{\circ} \mathrm{C}, " \mathrm{~J}$. Nucl. Mater. 192, 107-127 (1992).

WOLF, 1994

S. Wolf, N. L. Dietz, J. A. Fortner, E. C. Buck, N. R. Brown, and J. K. Bates, to be published in Spectrum '94. Atlanta, GA, August 15-18,'1994. 


\section{APPENDIX I}

\section{TERMINOLOGY}

\section{$\underline{\text { Acronyms and Initialisms }}$}

$\begin{array}{ll}\text { ABS } & \text { aqueous biphasic separation } \\ \text { AEM } & \text { analytical electron microscopy } \\ \text { ANL } & \text { Argonne National Laboratory } \\ \text { BEEMTM } & \text { better electron microscopy (trade name for type of capsule) } \\ \text { BSE } & \text { backscattered electrons } \\ \text { CBED } & \text { convergent beam electron diffraction } \\ \text { DOE } & \text { U.S. Department of Energy } \\ \text { EDS } & \text { energy dispersive X-ray spectroscopy } \\ \text { EELS } & \text { electron energy loss spectroscopy } \\ \text { EPA } & \text { U.S. Environmental Protection Agency } \\ \text { FEMP } & \text { Fernald Environmental Management Project } \\ \text { ID } & \text { Integrated Demonstration } \\ \text { LANL } & \text { Los Alamos National Laboratory } \\ \text { ORNL } & \text { Oak Ridge National Laboratory } \\ \text { SAED } & \text { selected area electron diffraction } \\ \text { SEM } & \text { scanning electron microscopy } \\ \text { PEELS } & \text { parallel electron energy loss spectroscopy } \\ \text { TEM } & \text { transmission electron microscopy } \\ \text { XAS } & \text { X-ray absorption spectroscopy } \\ \text { XANES } & \text { X-ray absorption near-edge structure } \\ \text { XAFS } & \text { X-ray absorption extended fine structure } \\ \text { XRD } & \text { X-ray diffraction }\end{array}$

Sites

$\begin{array}{ll}\text { A14 } & \text { soil sample, incinerator site } \\ \text { SP2-3 } & \text { core soil sample, storage pad } \\ \text { SP4 } & \text { core soil sample, operable unit 3, storage pad area } \\ \text { SP5 } & \text { core soil sample, operable unit 3 } \\ \text { SP9 } & \text { core soil sample, incinerator site } \\ \text { Dithionite } & \text { Reducing agent } \\ \text { Tiron } & \text { Complexing agent (1,2-dihydroxy-3,5-benzenedisulfonic acid) }\end{array}$


Distribution for ANL-94/38

Internal:

J. M. Andrew

J. S. Devgun

J. S. Luo

J. K. Bates

N. L. Dietz

J. J. Mazer

J. E. Battles

J. Fortner

C. Negri

E. C. Buck (5)

J. E. Harmon

T. G. Surles

D. J. Chaiko

J. E. Helt

J. C. Cunnane

J. J. Laidler

D. J. Wronkiewicz

TIS Files

\section{External:}

DOE-OSTI (2)

ANL-E Library (2)

ANL-W Library

Manager, Chicago Operations Office, DOE

J. C. Haugen, DOE-CH

S. L. Webster, DOE-CH

Chemical Technology Division Review Committee Members:

E. R. Beaver, Monsanto Company, St. Louis, MO

D. L. Douglas, Consultant, Bloomington, $M N$

R. K. Genung, Oak Ridge National Laboratory, Oak Ridge, TN

J. G. Kay, Drexel University, Philadelphia, PA

G. R. St. Pierre, Ohio State University, Columbus, $\mathrm{OH}$

J. Stringer, Electric Power Research Institute, Palo Alto, CA

J. B. Wagner, Arizona State University, Tempe, AZ

T. G. Adams, B. Koh \& Associates, Inc., Springville, NY

M. Ally, Oak Ridge National Laboratory, Oak Ridge, TN

J. A. Apps, Lawrence Berkeley Laboratory, Berkeley, CA

A. Armstrong, Oak Ridge National Laboratory, Oak Ridge, TN

L. R. Avens, Los Alamos National Laboratory, Los Alamos, NM

J. P. Bibler, Westinghouse Savannah River Company, Aiken, SC

J. Brainard, Los Alamos National Laboratory, Los Alamos, NM

E. Bramlitt, Kirtland Air Force Base, Kirtland, NM

N. R. Brown, USDOE, Richland Operations Office, Richland, WA

B. J. Carlson, Advanced Recovery Systems, Erwin, TN

L. O. Dworjahyn, Westinghouse Savannah River Company, Aiken, SC

R. S. Dyer, U.S. Environmental Protection Agency, Washington, DC

M. Eagle, U.S. Environmental Protection Agency, Washington, DC

N. Edwards, Oak Ridge National Laboratory, Oak Ridge, TN

R. C. Ewing, University of New Mexico, Albuquerque, NM

C. W. Francis, Oak Ridge National Laboratory, Oak Ridge, TN

D. Gombert, Lockheed Idaho Technology Company, Idaho Falls, ID 
N. Jacob, Advanced Recovery Systems, Erwin, TN

N. R. Johnson, Thermo Analytical Inc., Albuquerque, NM

M. Krstich, FERMCO, Cincinnati, OH

S. Y. Lee, Oak Ridge National Laboratory, Oak Ridge, TN

H. L. Lomasney, ISOTRON, Advanced Polymer Technology, New Orleans, LA

M. Malone, USDOE, Office of Technology Development, Germantown, MD

C. Mason, Los Alamos National Laboratory, Los Alamos, NM

G. Matthern, Idaho National Engineering Laboratory, Idaho Falls, ID

D. Morris, Los Alamos National Laboratory, Los Alamos, NM

K. Nix, Sanford Cohen \& Associates, Inc., McLean, VA

K. R. Nuhfer, FERMCO, Cincinnati, OH (5)

D. L. Perry, Lawrence Berkeley Laboratory, Berkeley, CA

R. Ryan, EG\&G Rocky Flats Plant, Golden, CO

J. Schwing, FERMCO, Cincinnati, OH

R. C. Smalley, RUST Environment \& Infrastructure, Aiken, SC

R. Stead, FERMCO, Cincinnati, $\mathrm{OH}$

C. Sutton, FERMCO, Cincinnati, OH

V. Tidwell, Sandia National Laboratory, Albuquerque, NM

M. Truex, Pacific Northwest Laboratory, Richland, WA

F. J. Wobber, USDOE, Health and Environmental Research, Germantown, MD

D. York, Los Alamos National Laboratory, Los Alamos, NM 